ARTICLE

\title{
Coat proteins of necroviruses target 14-3-3a to subvert MAPKKK $\alpha$-mediated antiviral immunity in plants
}

Zongyu Gao (1) ', Dingliang Zhang (1) ', Xiaoling Wang ${ }^{1}$, Xin Zhang ${ }^{1}$, Zhiyan Wen', Qianshen Zhang $\mathbb{D}^{1}$, Dawei Li id ${ }^{1}$, Savithramma P. Dinesh-Kumar (1) ${ }^{2} \&$ Yongliang Zhang $\mathbb{B}^{1 \times}$

Mitogen-activated protein kinase (MAPK) cascades play an important role in innate immunity against various pathogens in plants and animals. However, we know very little about the importance of MAPK cascades in plant defense against viral pathogens. Here, we used a positive-strand RNA necrovirus, beet black scorch virus (BBSV), as a model to investigate the relationship between MAPK signaling and virus infection. Our findings showed that BBSV infection activates MAPK signaling, whereas viral coat protein (CP) counteracts MAPKKK $\alpha$ mediated antiviral defense. CP does not directly target MAPKKK $\alpha$, instead it competitively interferes with the binding of 14-3-3a to MAPKKK $\alpha$ in a dose-dependent manner. This results in the instability of MAPKKK $\alpha$ and subversion of MAPKKK $\alpha$-mediated antiviral defense. Considering the conservation of 14-3-3-binding sites in the CPS of diverse plant viruses, we provide evidence that 14-3-3-MAPKKK $\alpha$ defense signaling module is a target of viral effectors in the ongoing arms race of defense and viral counter-defense.

\footnotetext{
${ }^{1}$ State Key Laboratory of Agro-Biotechnology and Ministry of Agriculture Key Laboratory of Soil Microbiology, College of Biological Sciences, China Agricultural University, 100193 Beijing, China. ${ }^{2}$ Department of Plant Biology and The Genome Center, College of Biological Sciences, University of California, Davis, Davis, CA 95616, USA. 凶email: cauzhangyl@cau.edu.cn
} 
$\mathrm{n}$ nature, plants are sessile stores of nutriment, thus frequently being attacked by numerous pests and pathogens, including insects, bacteria, fungi, and oomycetes. In order to survive, plants have developed a two-layered innate immune system to defend against invading pathogens ${ }^{1}$. Pattern-recognition receptors (PRRs) on the plasma membrane recognize pathogen/ microbe-associated molecular patterns (PAMPs/MAMPs), triggering a series of downstream defense responses, including calcium flux, production of reactive oxygen species (ROS), activation of mitogen-activated protein kinase (MAPK) cascades and upregulation of defense genes. This perception of PAMPs/ MAMPs constitutes the first layer of plant protection against pathogen attack and is referred to as pattern-triggered immunity $(\mathrm{PTI})^{2,3}$. To establish successful infections, pathogens secrete effectors into the plant cell to suppress PTI, resulting in effectortriggered susceptibility (ETS) ${ }^{1}$. Plants have evolved resistance (R) proteins to perceive these effectors and initiate a second layer of immunity named effector-triggered immunity (ETI), which is generally stronger and lasting longer than PTI and often accompanied by hypersensitive responses (HR), a type of cell death to confine pathogens to the infection sites ${ }^{4}$.

It is widely accepted that RNA silencing is the first layer of plant defense against viruses ${ }^{5,6}$. In addition, plants also have evolved $R$ proteins that recognize viral proteins as effectors and activate ETI similar to that employed in response to nonviral pathogens ${ }^{7}$. So far, no classical PAMPs have been found in plant-virus interactions. However, over the past decade, a growing body of evidence suggests that plants also deploy PTI to limit virus infection. For example, co-receptors such as brassinosteroid insensitive 1 -associated kinase 1 (BAK1) and BAK1-like kinase 1 involved in PTI in Arabidopsis thaliana against nonviral pathogens are also shown to contribute to plant defense against several RNA viruses, including turnip crinkle virus $(\mathrm{TCV})^{8}$, oilseed rape mosaic virus (ORMV), tobacco mosaic virus (TMV) ${ }^{9}$, and plum pox virus $(\mathrm{PPV})^{10}$. MAPK4 homologs in soybean (Glycine max) are reported to negatively regulate $S A$ accumulation and defense against soybean mosaic virus (SMV) ${ }^{11}$. Distinct from BAK1mediated PTI, the nuclear shuttle protein-interacting kinase 1 (NIK1)-mediated antiviral signaling is specific to plant DNA viruses belonging to the genus Begomovirus of Geminiviridae family, and causes translocation of the ribosomal protein L10 (RPL10) to the nucleus for translational suppression of plant defense $\mathrm{e}^{12,13}$. Geminivirus nuclear shuttle protein (NSP) overcomes this defense by interfering with NIK1-mediated nuclear relocalization of RPL10A ${ }^{12}$. Some RNA viruses have also been reported to counter PTI responses. For example, coat protein (CP) of PPV and movement protein (MP) of cucumber mosaic virus (CMV) were reported to suppress flg22-induced ROS production and PTI marker genes in Arabidopsis and Nicotiana benthamiana ${ }^{10,14}$. Cauliflower mosaic virus (CaMV) silencing suppressor P6 was shown to suppress ROS burst and SAdependent autophagy ${ }^{15}$. Although these studies show some evidence suggesting an association of PTI in antiviral immunity, the functional role of PTI against plant viruses, especially positivestrand RNA viruses, and the molecular mechanisms underlying viral suppression of PTI remain to be fully characterized.

Although PTI and ETI are activated mainly through distinct immune receptors, they share some features of the signaling machinery and initiate many common responses ${ }^{16,17}$. For example, MAPK cascades serve as a convergent point downstream of PTI and ETI ${ }^{18,19}$. MAPK cascades are composed of three tiers of kinases, MAPKs-MAPKKs-MAPKKKs, and activated through phosphorylation by their upstream kinases in turn, which play a central role in stress signal transduction from upstream receptors to downstream targets ${ }^{20}$. Two main MAPK cascades are reported to be activated in Arabidopsis during $\mathrm{PTI}^{21}$, one is consisted of MAPKKK3/MAPKKK5-MKK4/MKK5MPK3/MPK6 $6^{22,23}$ and the other is consisted of MEKK1-MKK1/ MKK2-MPK4 $4^{24,25}$. In addition, several components of MAPK cascades are also reported to play important roles in $\mathrm{R}$ proteinmediated ETI and often associated with HR cell death. For example, in Arabidopsis, MPK3 and MPK6 are activated by RPS2mediated immunity ${ }^{26}$. In tobacco, two MAPKs, salicylic acidinduced protein kinase (SIPK) and wounding-induced protein kinase (WIPK), the orthologs of MPK6 and MPK3 in Arabidopsis ${ }^{20}$, are involved in $N$ gene-mediated resistance ${ }^{27,28}$ and cell death ${ }^{29,30}$. In tomato, two MAPKKs, MEK1 and MEK2, and two MAPKs, NTF6 and WIPK, contribute to Pto-mediated immunity ${ }^{31}$, and overexpression of a tomato MAPKKK, LeMAPKKKa, results in cell death ${ }^{32}$. Some pathogen effectors were reported to target MAPK cascades to inhibit defense responses such as AvrRpt2 ${ }^{33}$, HopAI1 ${ }^{34}$, and HopF2 ${ }^{35}$. Recently, geminivirus tomato yellow leaf curl China virus (TYLCCNV) encoded $\beta C 1$ was reported to directly target MKK2 and MPK4 to suppress plant immunity ${ }^{36}$. However, whether positive-strand RNA viruses target MAPK cascades remains to be determined.

In this study, we used a positive-strand RNA virus, beet black scorch virus (BBSV), as a model to explore the functional role of plant innate immune signaling in virus infection and the counterdefensive strategies employed by virus to overcome this layer of defense. We demonstrate that MAPKKKa-mediated defense against BBSV infection in $N$. benthamiana is correlated with the expression of a series of defense-related genes such as PR1A, $E R F 1 B$, and $H I R 1$, whereas viral CP can subvert MAPKKKamediated antiviral innate immune response by targeting 14-3-3a. We also provide evidence that the CP targeting of MAPKKKa14-3-3a defense signaling module also occurs in the infection of the other two plant RNA viruses in the family Tombusviridae. Our study provides mechanistic insight into understanding the suppression of plant innate immunity by RNA viruses.

\section{Results}

MAPKKKa plays an antiviral role during BBSV infection. MAPKKKa has been reported to positively regulate cell-death signaling associated with plant immunity ${ }^{32}$. However, little is known about its role in virus infection. We used BBSV as a model to explore the role of MAPKKKa in plant-virus infection. To monitor the virus infection, we used a self-assembling split superfolder green fluorescent protein (sfGFP) system ${ }^{37}$. In this system, 11 th $\beta$-strand of sfGFP (sfGFP11) was fused to the N-terminus of $\mathrm{CP}$ in the BBSV infectious clone to generate BBSV-sfGFP 11 (Fig. 1a). Co-expression of BBSV-sfGFP 11 with sfGFP1-10 $\beta$ strand (sfGFP1-10) in plant cells will result in the GFP fluorescence, which can be used to indicate the infection of BBSV. We then knocked down the expression of MAPKKKa by using intron spliced hairpin RNAi vector-mediated gene silencing ${ }^{38}$, and observed increased GFP fluorescence and CP accumulation in $M A P K K K \alpha$-RNAi leaves compared with the empty vector (EV) control (Fig. 1b, c). Downregulation of MAPKKKa using this strategy was validated by RT-qPCR (Fig. 1d). To further confirm these results, we generated $N$. benthamiana MAPKKK $\alpha$-knockout (KO) plants via CRISPR-Cas9 gene editing. MAPKKKa has a homolog (MAPKKKa-2) in N. benthamiana (Supplementary Fig. 1a) and Sanger sequencing indicated deletions at gRNA targeting site within two $M A P K K K \alpha$ genes in $M A P K K K \alpha-\mathrm{KO}$ plants (Fig. 1e and Supplementary Fig. 1b). MAPKKK $\alpha-K O$ plants accumulated increased CP upon BBSV inoculation (Fig. 1f). These results indicate that MAPKKKa plays an antiviral role during BBSV infection.

To further determine the role of MAPKKKa in BBSV infection, we overexpressed MAPKKKa and a kinase-inactive mutant, 
a

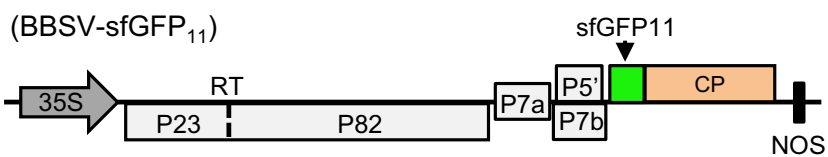

C

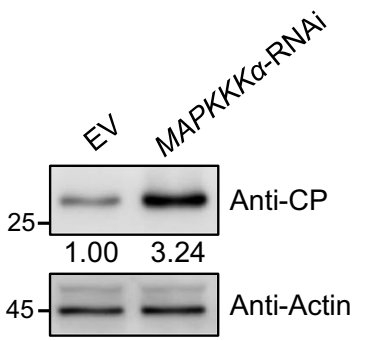

d

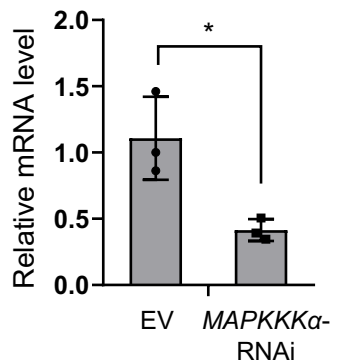

g

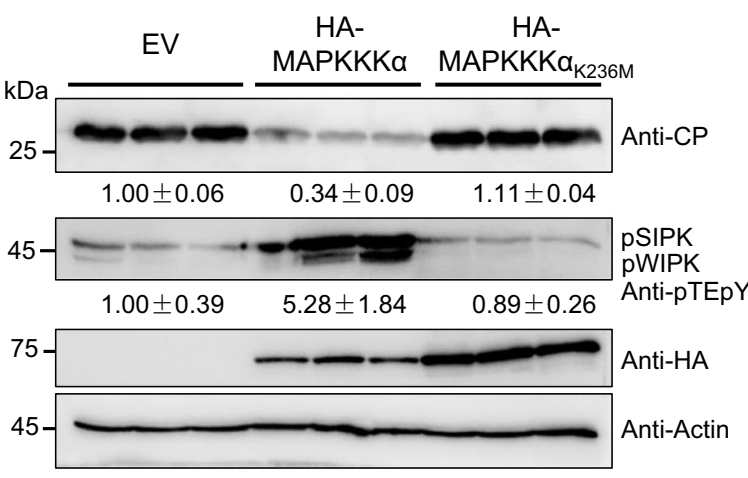

h

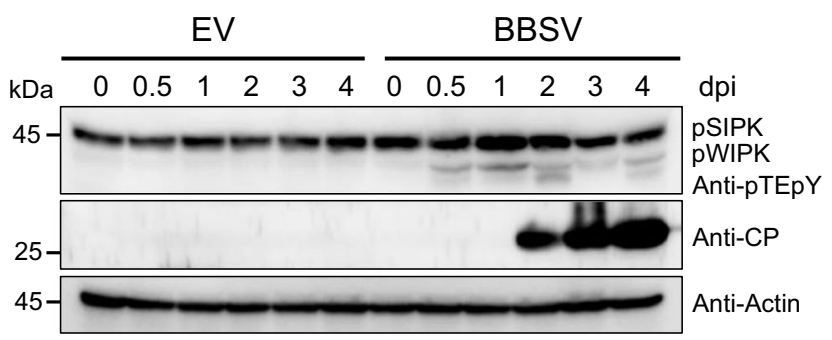

j

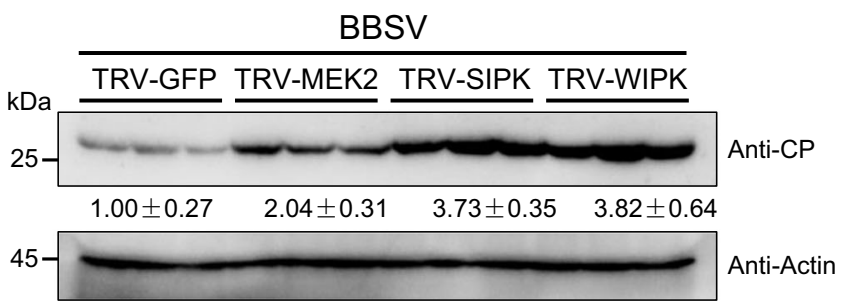

b

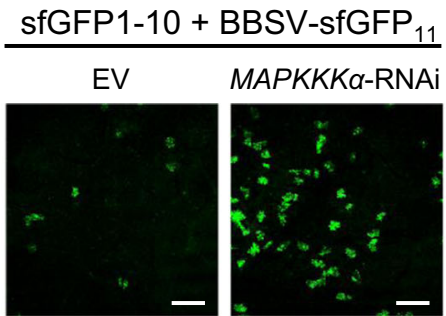

e

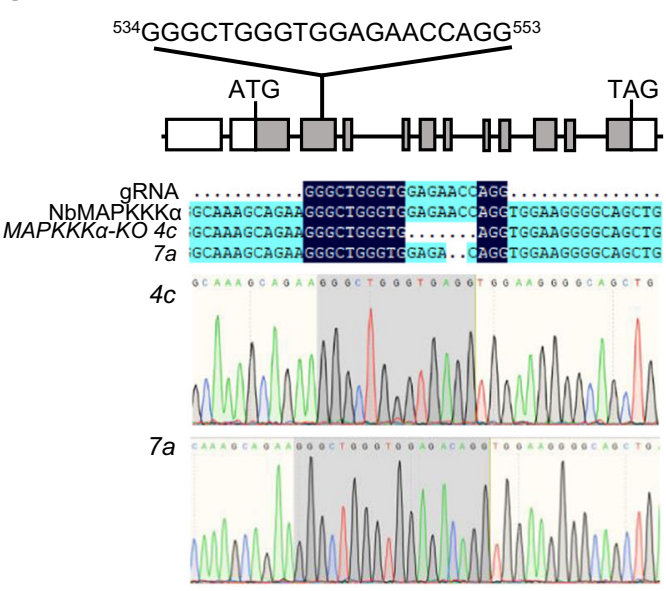

f

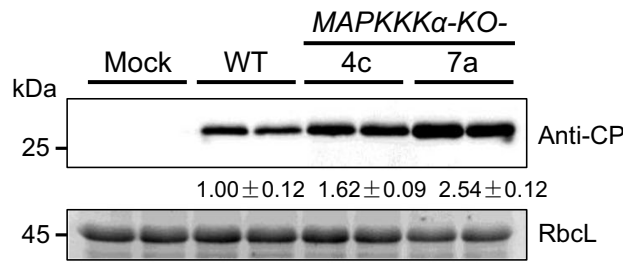

i

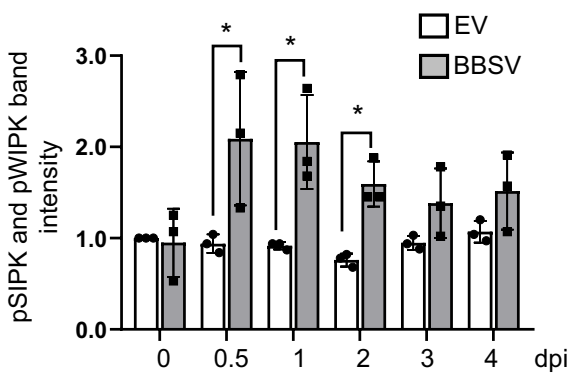

k

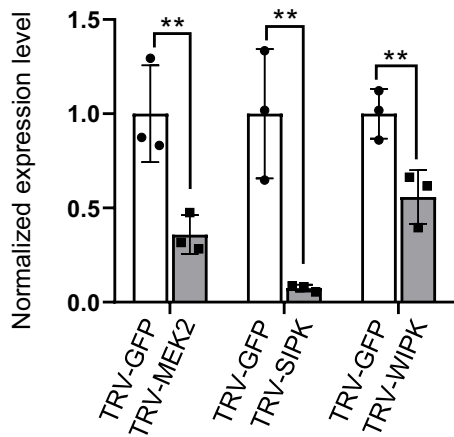

MAPKKKa $_{\text {K236M }}$ (K236 is a conserved ATP binding site essential for the kinase activity of MAPKKKa ${ }^{32}$ ) followed by BBSV inoculation. At 3-day post infiltration (dpi), the accumulation of BBSV CP was decreased in leaves overexpressing MAPKKKa compared with EV control. However, overexpression of $\mathrm{MAPKKKa}_{\mathrm{K} 236 \mathrm{M}}$ had no significant effect on BBSV CP accumulation (Fig. 1g, top panel). Moreover, the phosphorylation levels of two MAPKs, NbSIPK, and NbWIPK, which were reported to act downstream of MAPKKKa ${ }^{32}$ were higher in the leaves overexpressing MAPKKKa compared with EV and MAPKKKa $_{\text {K236M }}$ (Fig. 1g, middle panel). Furthermore, the expression of MAPKKKa induced cell death but not by 
Fig. 1 MAPKKK $\alpha$ plays an antiviral role during BBSV infection. a Schematic representation of BBSV-sfGFP 11 . 11th $\beta$-strand of super-folder GFP (sfGFP 11 ) is fused to the N-terminus of CP in BBSV infectious clone. $\mathbf{b}$ Knockdown of MAPKKK $\alpha$ promotes BBSV infection. Agrobacterium containing hairpin MAPKKK $\alpha$ or the control empty vector (EV) was infiltrated into half of $N$. benthamiana leaves, respectively. Twenty-four hours later, a mixture of Agrobacterium harboring BBSV-sfGFP 11 and sfGFP1-10 constructs was infiltrated into the pre-infiltrated leaves. GFP fluorescence was visualized by confocal microscopy at $5 \mathrm{dpi}$. Scale bars $=100 \mu \mathrm{m}$. c The expression level of BBSV CP in the infiltrated leaves was examined by western blot analysis using an anti-CP antibody. Actin served as the loading control. For panels $\mathbf{b}$ and $\mathbf{c}$, the experiments were repeated three times with similar results. $\mathbf{d}$ RT-qPCR to confirm the downregulation of MAPKKK $\alpha$. Values represent \pm SD of the mean from three biological replicates. An asterisk indicates the significant difference $\left({ }^{\star} P=0.0104\right)$ based on one-sided unpaired Student's $t$ test. e Locus of the single guide RNA target in the genomic fragment of NbMAPKKK $\alpha$. Exons are represented by gray boxes, UTRs by white boxes, and introns by black lines. In T2 transformants, deletions were detected in two NbMAPKKK $\alpha$-KO lines. f Western blot analysis of BBSV CP levels in the infiltrated leaves of wild-type (WT) or NbMAPKKK $\alpha$-KO plants using an anti-CP antibody. RbcL served as the loading control. The experiment was repeated three times with similar results. $\mathbf{g}$ Overexpression of MAPKKK $\alpha$ inhibits BBSV infection. Agrobacterium containing MAPKKK $\alpha$ or MAPKKK $\alpha_{K 236 \mathrm{M}}$ or the control empty vector (EV) was infiltrated into different N. benthamiana leaves. Agrobacterium harboring BBSV infectious clone was infiltrated $24 \mathrm{~h}$ later. The accumulation levels of BBSV or phosphorylated NbSIPK and NbWIPK were detected by western blot analysis with an anti-CP or anti-phospho-p44/42 MAPKs (anti-pTEpY) antibody. Actin protein served as the loading control. Each lane represents a sample from individual experiments. h. MAPK activation in BBSV-infected N. benthamiana. Eight-leaf-stage N. benthamiana plants were infiltrated with Agrobacterium carrying empty vector (EV) or BBSV infectious clone. Infiltrated leaves were collected at indicated time points and subjected to western blot analysis with an anti-pTEpY or anti-BBSV CP antibody. Actin protein served as the loading control. i Quantification of bands from blot in panel $\mathbf{h}$, with pSIPK and $\mathrm{pWIPK}$ abundance normalized to the intensity of $\mathrm{EV}$ control at $\mathrm{O}$ h. Values represent $\pm \mathrm{SD}$ of the mean from three biological replicates. An asterisk indicates the significant difference $\left({ }^{\star} P=0.0498,0.0284,0.0134\right.$, respectively) based on one-sided paired Student's $t$ test. $\mathbf{j}$ Western blot analysis of BBSV CP accumulation in the TRV-GFP control, TRV-NbMEK2, TRV-NbSIPK, and TRV-NbWIPK inoculated N. benthamiana plants. Actin protein served as the loading control. $\mathbf{k}$ RT-qPCR to confirm the downregulation of NbMEK2, NbSIPK, and NbWIPK. Values represent \pm SD of the mean from three biological replicates. An asterisk indicates the significant difference ${ }^{\star \star} P=0.0043,0.0068,0.0085$, respectively) based on one-sided unpaired Student's $t$ test. For panels $\mathbf{h}$ and $\mathbf{j}$, the experiments were repeated three times with similar results.

MAPKKKa ${ }_{\mathrm{K} 236 \mathrm{M}}$ (Supplementary Fig. 2). The expression of MAPKKKa and MAPKKKa $\alpha_{K 236 \mathrm{M}}$ was confirmed by western blot (Fig. 1g, middle panel). These results suggest that MAPKKKa may negatively regulate BBSV infection via activation of the downstream MAPK cascades.

To analyze whether MAPK cascades were activated during BBSV infection, we infiltrated N. benthamiana with Agrobacterium containing BBSV infectious cDNA and monitored the phosphorylation status of NbSIPK and NbWIPK at different time points. We observed a significant increase in phosphorylation levels of NbSIPK and NbWIPK at 0.5-, 1-, and 2-day post BBSV inoculation (Fig. 1h, i). These results indicate that the MAPK cascade is activated at the early stage of BBSV infection.

To further test whether the activated MAPK signaling is involved in defense against BBSV infection, we performed loss-offunction assays of $N b M E K 2, N b S I P K$, and $N b W I P K$ by using Tobacco rattle virus (TRV)-based gene silencing (VIGS). CP accumulation in NbMEK2, NbSIPK, or NbWIPK silenced plants was higher than in the control TRV-GFP inoculated plants (Fig. 1j). The silencing efficiency of NbMEK2, NbSIPK, or NbWIPK was confirmed by RT-qPCR (Fig. 1k). Together, these results indicate that $\mathrm{BBSV}$ infection activates the MAPKKKaMEK2-SIPK/WIPK cascade, which in turn induces plant defense responses against BBSV infection.

MAPKKKa-mediated antiviral response associates with the expression of defense-related genes. To further investigate the mechanism underlying MAPKKKa-mediated antiviral response, we performed RNA-seq analysis in wild-type (WT) and the $M A P K K K \alpha-K O$ plants during BBSV infection. We collected leaves from mock- and BBSV-infected plants at 0.5, 1, and 2 dpi and performed RNA-Seq. We observed upregulation of 911, 3662, and 2570 genes in WT plants at $0.5,1$, and 2 dpi, respectively (Fig. 2a, $\mathrm{b}$ and Supplementary Data 1). The Kyoto Encyclopedia of Genes and Genomes (KEGG) enrichment analysis indicated that these upregulated genes were highly enriched in plant-pathogen interaction process, MAPK signaling pathway, and plant hormone signal transduction (Fig. 2c). Further analysis showed that 370 genes, which were upregulated in WT plants after BBSV infection, were downregulated in the comparisons KO-BBSV vs WT-BBSV
(Fig. 2d, e and Supplementary data 2). KEGG analysis revealed that these downregulated genes were also enriched in plant-pathogen interaction process and MAPK signaling pathway (Fig. 2f). We selected three defense-related genes, including PATHOGENESIS-RELATED PROTEIN 1A (PR1A), ETHYLENERESPONSIVE TRANSCRIPTION FACTOR $1 B(E R F 1 B)^{39}$, and HYPERSENSITIVE-INDUCED RESPONSE PROTEIN 1 (HIR1) ${ }^{40}$ for further RT-qPCR analysis, and the results were consistent with the RNA-seq data (Fig. 2g). Together, these results suggest that MAPKKKa-mediated defense against BBSV infection is correlated with the expression of defense-related genes.

BBSV CP suppresses MAPKKKa-mediated antiviral immunity through its interaction with 14-3-3a. We noted that the phosphorylation levels of NbSIPK and NbWIPK declined two days after BBSV infection (Fig. 1h, i), suggesting that BBSV may have evolved with strategies to suppress MAPK activity. To test if BBSV-encoded proteins could suppress MAPKKKa-mediated signal transduction, we co-expressed different BBSV proteins and GFP control with HA-MAPKKKa, which was controlled by an estradiol-inducible system. Trypan blue staining of leaf tissues and the electrolyte-leakage assay showed that only CP of BBSV suppressed MAPKKKa-induced cell death while other viral proteins showed a similar cell-death phenotype to that of the GFP control (Fig. 3a, b). Western blot analysis with anti-GFP antibody confirmed the expression of these proteins (Supplementary Fig. 3a). Together, these results demonstrate that BBSV CP plays a role in suppressing MAPKKKa-mediated defense.

We reasoned that $\mathrm{CP}$ may suppress MAPKKKa-mediated defense by directly interacting with MAPKKKa and inhibiting its activity. To test this, we performed bimolecular fluorescence complementation (BiFC) assay. As a positive control, CP-YFPn and $\mathrm{CP}-\mathrm{YFP}$ c resulted in strong reconstituted YFP signals, yet no fluorescence signal was observed in the leaves co-expressing either CP-YFPc and MAPKKKa $\alpha_{K 236 M}-$ YFPn or CP-YFPn and MAPKKKa $\alpha_{\mathrm{K}_{236 \mathrm{M}}}$-YFPc (Supplementary Fig. 4a). The expression of proteins was confirmed by western blot analysis (Supplementary Fig. 3b, c). Yeast two-hybrid (Y2H) assay showed that yeast expressing $\mathrm{AD}-\mathrm{MAPKKKa}$ and $\mathrm{BD}-\mathrm{CP}$ or $\mathrm{AD}-\mathrm{CP}$ and $\mathrm{BD}$ MAPKKKa failed to grow on the drop-out media compared with 
a

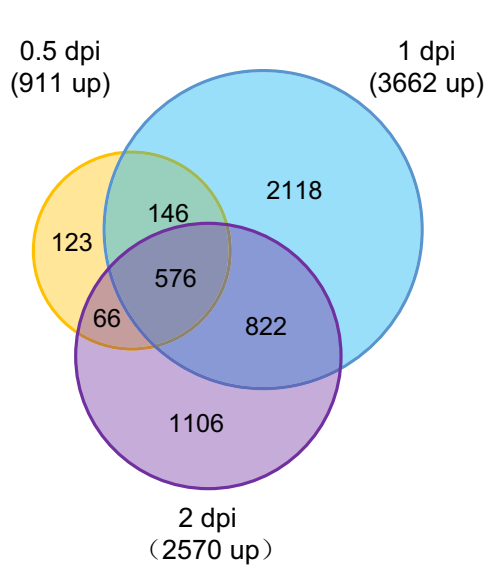

d

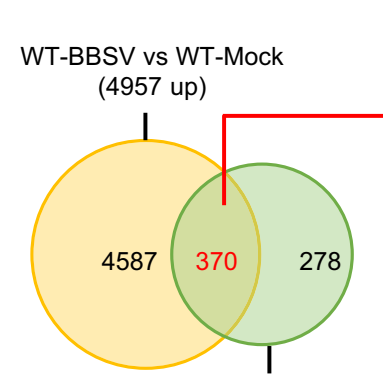

KO-BBSV vs WT-BBSV (648 down)

g

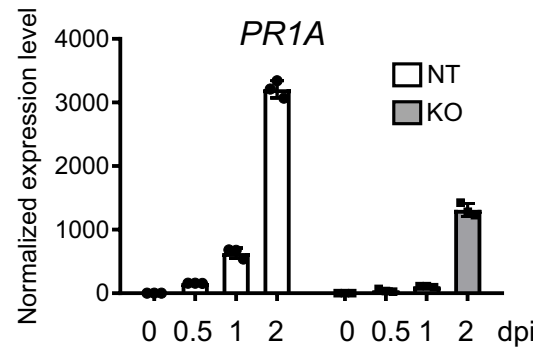

b

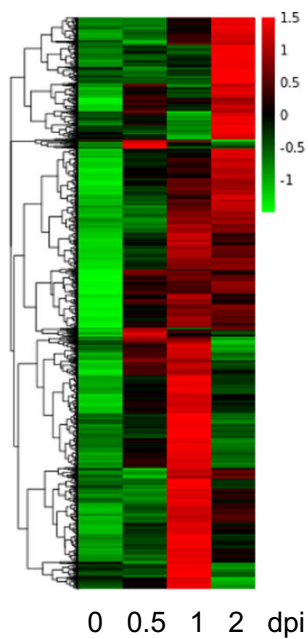

C

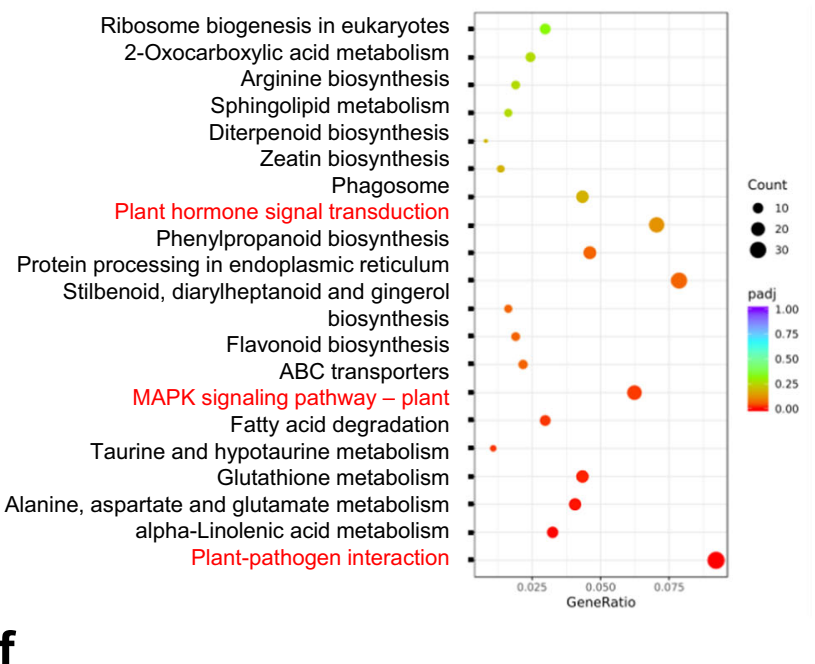
Biosynthesis of unsaturated fatty acids . Sesquiterpenoid and triterpenoid biosynthesis Valine, leucine and isoleucine degradation : Phenylpropanoid biosynthesis : Cysteine and methionine metabolism . Linoleic acid metabolism * Peroxisome . MAPK signaling pathway - plant . alpha-Linolenic acid metabolism Autophagy-other * Glutathione metabolism Pantothenate and CoA biosynthesis : Butanoate metabolism * Zeatin biosynthesis . Glucosinolate biosynthesis . Alanine, aspartate and glutamate metabolism . Taurine and hypotaurine metabolism . beta-Alanine metabolism . Plant-pathogen interaction .

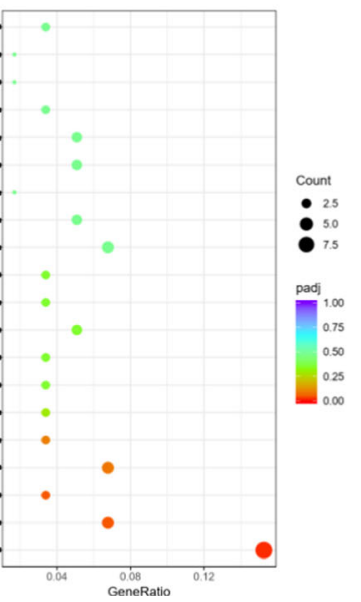

Fig. 2 RNA-seq analyses of non-transgenic and MAPKKK $\boldsymbol{\alpha}-\mathbf{K O}$ plants in response to BBSV infection. a Venn diagrams showing overlaps of upregulated genes in WT-BBSV at different time points vs WT-Mock. b Heatmaps showing hierarchical cluster analysis of all differentially expressed genes. Data were collected from three biological replicates, each containing a pool of three individual plants. The resulting $P$ values were adjusted using Benjamini and Hochberg's approach for controlling the false discovery rate (padj). Padj $<=0.05$ and $\mid \log 2$ (foldchange) $\mid>=1$ were set as the threshold for significantly differential expression. c The Kyoto Encyclopedia of Genes and Genomes (KEGG) enrichment analyses of all upregulated genes in BBSV-infected plants. d Venn diagrams showing overlaps of 4957 upregulated genes in WT-BBSV vs WT-Mock and 648 downregulated genes in KO-BBSV vs WT-BBSV. e Heatmaps showing hierarchical cluster analysis of 370 differentially expressed genes shown in (d). f KEGG enrichment analyses of 370 differentially expressed genes shown in (d). $\mathbf{g}$ RT-qPCR assay to validate the accuracy of the transcriptome data for these differentially expressed genes shown in (d). $E F-1 \alpha$ was used as the internal reference gene to normalize the relative expression. Values are mean \pm SD from three biological repeats.

the positive control (Supplementary Fig. 4b). These results indicate that CP does not directly interact with MAPKKKa.

To identify the targets of BBSV CP that could interfere with the MAPKKKa activity, we performed immunoprecipitation (IP) of CP-3 $\times$ FLAG and separated immunoprecipitates by SDS-PAGE followed by silver staining. A distinct band was visible in the IP products from $\mathrm{CP}-3 \times \mathrm{FLAG}$ but the corresponding band was absent in the lane of GFP-3×FLAG control (Fig. 3c). The band was excised from the gel and analyzed by liquid chromatography coupled to tandem mass spectrometry (LC-MS/MS). Several 
a

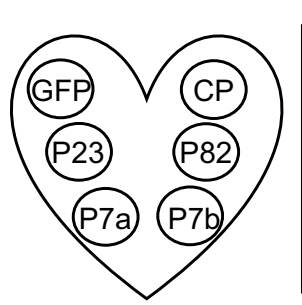

C

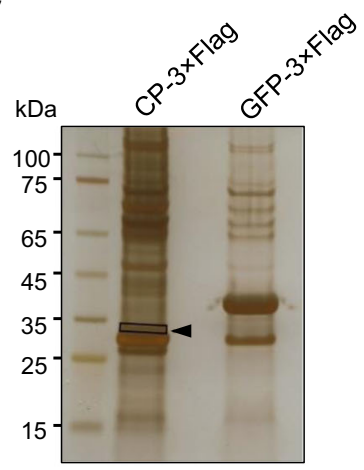

XVE :: MAPKKKa +

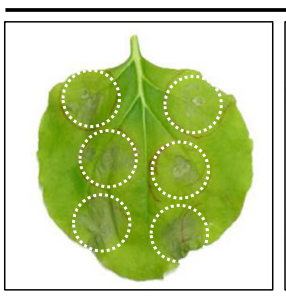

d

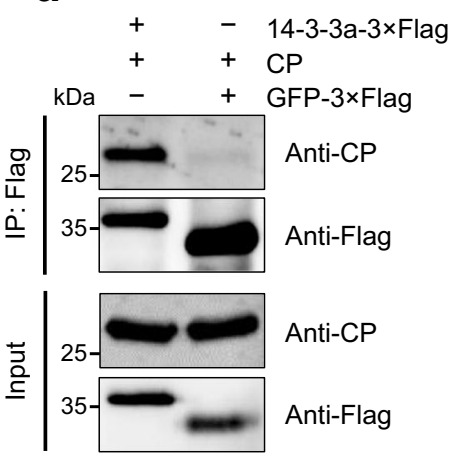

b

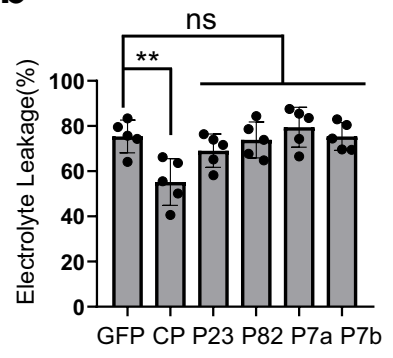

e ++ - GST-14-3-3a

$-\quad+$ GST

$+\quad+$ His-CP

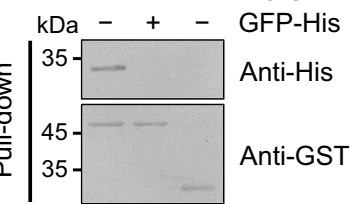

\begin{tabular}{l|l}
$35-\square-\square$ & Anti-His \\
$45-\square$ & Anti-GST \\
$35-$ &
\end{tabular}

$\mathbf{f}$ Nb14-3-3a MASPREENVYLAKLAEQAERYEEMVEFMEKVVGA - GDDELTVEERNLLSVAYKNVIGARRASWRI TFT7 (Tomato) MEKEREKQVYLARLAE QAERYDEMVEAMKAIAK - - MDVELTVEERNLVSVGYKXVI GARRASWRI GRF2 (Arabidopsis) MASGREEFVYMAKLAEQAERYEEMVEFMEKVSAAVDGDELTVEERNLLSVAYKNVIGARRASWRI zeta/delta (Human) - - MDKNELVQKAKLAEQAERYDDMAACMKSVTE - - QGAELSNEERNLLSVAYKNVVGARRSSWRV

Dimer-determinant

g
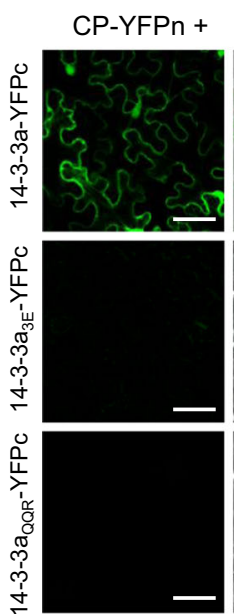

Merge
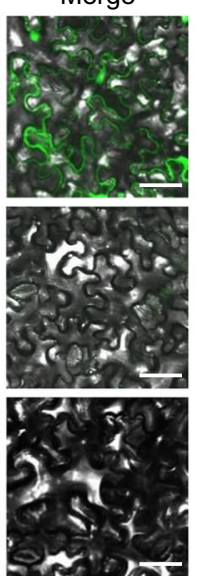

CP-YFPc +
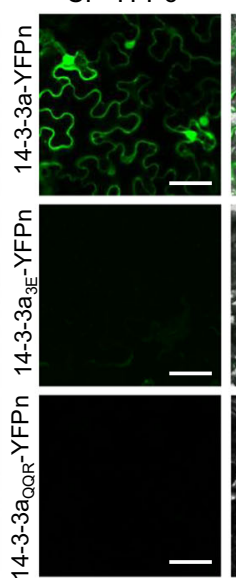

Merge

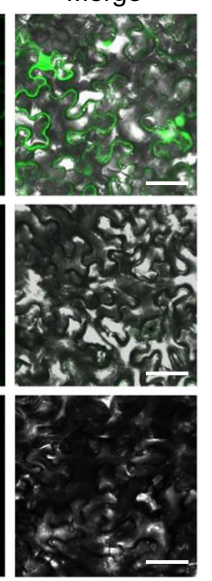

h

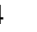

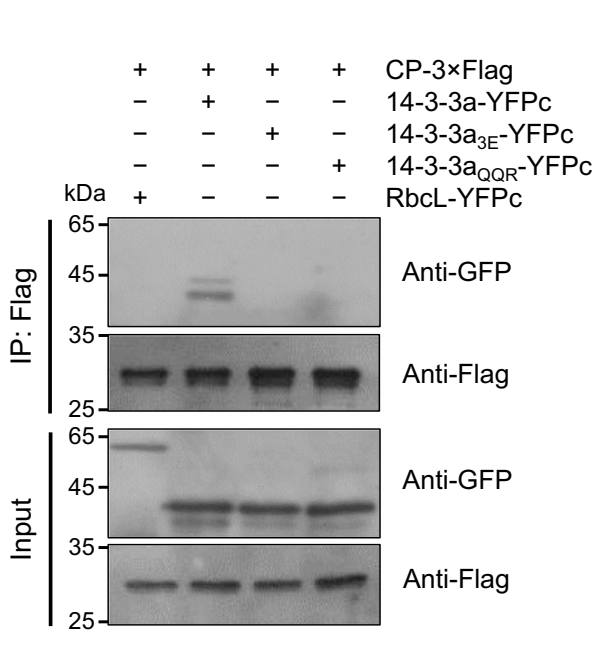

14-3-3 proteins were identified in the MS dataset (Supplementary Data 3). Considering the important role of 14-3-3 proteins in plant immunity ${ }^{41,42}$, we hypothesized that 14-3-3 proteins might take part in the plant response to BBSV infection. Among identified 14-3-3 proteins, $N$. tomentosiformis 14-3-3-like protein A (gi|697111701) showed the highest score, with $100 \%$ amino acid identity with $N$. benthamiana 14-3-3a (Supplementary Fig. 5). We then cloned 14-3-3a from $N$. benthamiana and used it as a surrogate for further analysis.

To investigate whether CP interacts with 14-3-3a in planta, we cloned full-length 14-3-3a from N. benthamiana and performed co-immunoprecipitation (Co-IP) assay. We found that CP coimmunoprecipitates with $14-3-3 \mathrm{a}-3 \times \mathrm{FLAG}$, but not with GFP-3 $\times$ FLAG control (Fig. 3d). BiFC experiments confirmed the interaction in planta (Fig. 3g, top panel). To see if CP interacts directly with 14-3-3a, we performed a GST pull-down assay. A GST tag was fused to the N-terminus of 14-3-3a and a $6 \mathrm{xHis}$ tag was fused to CP. GST and GFP-His served as negative controls. The result showed that GST-14-3-3a specifically binds to the His$\mathrm{CP}$ but not to the GFP-His control (Fig. 3e). Based on these results, we conclude that $\mathrm{CP}$ interacts with $14-3-3 \mathrm{a}$ in vivo and in vitro.

There are several conserved amino acids within animal 14-3-3s protein that determine its binding to the substrate ${ }^{43}$ and 
Fig. 3 CP suppresses MAPKKK $\alpha$-induced cell death by interacting with 14-3-3a. a BBSV CP suppresses the cell death induced by MAPKKK $\alpha$. Five different BBSV-encoded proteins or GFP control were co-expressed with HA-MAPKKK $\alpha$ controlled by an estradiol-inducible system in indicated leaf regions. $\beta$-estradiol was infiltrated into the leaves at $48 \mathrm{~h}$ after agroinfiltration. Leaves were stained by trypan blue, and representative photographs were taken at three days after estradiol treatment. $\mathbf{b}$ Quantification of cell death by measuring electrolyte leakage of leaves shown in (a). Error bars indicate \pm SD of the mean ( $n=5$ biologically independent plants). Asterisks indicated the significant difference based on one-way ANOVA analysis with Dunnett's multiple comparison test $\left({ }^{\star} P=0.0013\right)$. c Silver-stained SDS-PAGE gel image of CP-3×Flag and GFP-3×Flag protein immunoprecipitated using anti-Flag beads from BBSV-infected $N$. benthamiana leaf tissues. The band indicated by the rectangle was analyzed by LC-MS/MS. $\mathbf{d}$ Co-IP analysis of the interaction between 14-3-3a and CP. N. benthamiana leaves transiently expressing combinations of different proteins indicated above the panel were harvested at 3 dpi. Total proteins were immunoprecipitated with anti-Flag beads and detected by western blot with an anti-CP or anti-Flag antibody. e GST pull-down assay to detect the interaction between CP and 14-3-3a. Purified His-CP or His-GFP was incubated with GST-14-3-3a or GST protein control. After incubation with glutathione-Sepharose beads, the pull-down products were analyzed by western blot with an anti-His or anti-GST antibody. For panels c-e, the experiments were repeated three times with similar results. f Depiction of 14-3-3 N-terminal sequences alignment generated by UniPort (https://www.uniprot.org/ align/). 14-3-3 isoforms from different species were indicated on the left side. The underlined amino acids are required for dimerization of 14-3-3 proteins $^{44}$. The amino acids responsible for 14-3-3-ligand-binding activity are highlighted with asterisks ${ }^{43} \cdot \mathbf{g}$ BiFC analysis of the interaction between wildtype or mutant 14-3-3a and CP. CP and wild-type or mutant 14-3-3a fused to N or C-terminus of YFP were transiently co-expressed in N. benthamiana leaves. Confocal analysis was performed at $3 \mathrm{dpi}$. Representative results of at least three independent experiments are shown. Scale bars $=50 \mu \mathrm{m}$. $\mathbf{h}$ Co-IP analysis of the interaction between wild-type or mutant 14-3-3a and CP. N. benthamiana leaves transiently expressing combinations of different proteins were harvested at $3 \mathrm{dpi}$. Total proteins were immunoprecipitated with anti-Flag beads and detected by western blot with an anti-GFP or anti-Flag antibody. The experiment was repeated three times with similar results.

dimerization ${ }^{44}$. Amino acid sequence alignment indicates that the amino acids required for these functions are also conserved in plant 14-3-3s (Fig. 3f). To examine whether these amino acids are responsible for 14-3-3 dimerization and its binding to the $\mathrm{CP}$, two mutants, $14-3-3 \mathrm{a}_{\mathrm{OQR}}$, in which the amino acids at 12-LAE-14 was mutated to QQR, and $14-3-3 \mathrm{a}_{3 \mathrm{E}}$, in which the amino acids of $\mathrm{K} 52$, R59, and R63 were all mutated to E, were constructed. Only the mutation in LAE eliminated the dimerization of 14-3-3a (Supplementary Fig. 6), and both of these two mutants fail to interact with $\mathrm{CP}$ as shown in the BiFC and Co-IP assays (Fig. 3g, $\mathrm{h})$. The expression of proteins in BiFC assay was confirmed by western blot analysis (Supplementary Fig. 3d). These results indicate that both the dimerization and substrate binding activity of 14-3-3a is indispensable for its binding to CP.

Nb14-3-3a positively regulates MAPKKKa-mediated cell death. To test whether 14-3-3a plays a functional role in the activation of cell death through MAPKKKa in $N$. benthamiana, we performed BiFC and Co-IP assays. The results showed that the wild-type 143-3a, but not the 14-3-3a $\mathrm{a}_{3 \mathrm{E}}$ and $14-3-3 \mathrm{a}_{\mathrm{QQR}}$ mutants, interacts with MAPKKKa (Fig. $4 \mathrm{a}, \mathrm{b}$ ). The expression of proteins in BiFC assay was confirmed by western blot analysis (Supplementary Fig. 3b, c). We then examined the effect of 14-3-3a on MAPKKKa-induced cell death. Wild-type or mutant 14-3-3a was co-expressed with estradiol-induced HA-MAPKKKa protein, and cell death was evaluated at $3 \mathrm{dpi}$ after $12 \mathrm{~h}$ estradiol treatment. Trypan blue staining showed that overexpression of wild-type 143-3a significantly enhanced MAPKKKa-induced cell death compared with the GFP control (Fig. 4c). In contrast, coexpression of either $14-3-3 \mathrm{a}_{3 \mathrm{E}}$ or $14-3-3 \mathrm{a}_{\mathrm{QQR}}$ mutant with HAMAPKKKa showed an alleviated cell-death phenotype (Fig. 4c). An electrolyte-leakage assay substantiated the results shown in Fig. $4 \mathrm{c}$ by showing that electrolyte leakage was increased by about $25 \%$ with the expression of wild-type 14-3-3a and decreased by about $10 \%$ with the expression of 14-3-3a mutants compared with the GFP control (Fig. 4d), indicating a possible dominantnegative effect of these two mutants on MAPKKKa-induced cell death. The expression of wild-type 14-3-3a, mutant, and GFP proteins was confirmed by western blot analysis (Fig. $4 \mathrm{~g}$ ). We next tested the MAPKKKa-induced cell death in the Nb14-3-3asilenced leaves. Trypan blue staining and the electrolyte-leakage assay showed that MAPKKKa-induced cell death was dramatically decreased when 14-3-3a was silenced (Fig. 4e, f). Downregulation of 14-3-3a by RNAi was confirmed by western blot analysis with anti-14-3-3a antibody (Fig. 4h). These results indicate that 14-3-3a functions as a positive regulator of MAPKKKa-induced cell death.

We also found that the downregulation of 14-3-3a affects the accumulation of MAPKKKa protein, which can be partially rescued by the addition of the proteasome inhibitor MG132 (Fig. 4i). SIPK and WIPK phosphorylation levels were in line with MAPKKKa protein levels (Fig. 4i). RT-qPCR analysis showed that silencing of Nb14-3-3a had no obvious effects on the transcription of NbMAPKKK $\alpha$ (Supplementary Fig. 7), suggesting that Nb14-3-3a mainly regulated the abundance of NbMAPKKKa at the protein level. Together, these results demonstrate that 14-3-3a enhances MAPKKKa-mediated signaling by increasing the stability of MAPKKKa.

Nb14-3-3a-mediated antiviral defense depends on the MAPKKKa. To determine the functional role of 14-3-3a in viral infection, we transiently overexpressed wild-type and mutant 143-3a in N. benthamiana leaves and then mechanically inoculated BBSV virions at $24 \mathrm{~h}$ post infiltration (hpi). The accumulation of BBSV CP was greatly reduced in the leaves overexpressing wildtype 14-3-3a compared with the control leaves expressing GFP (Fig. 5a), indicating that overexpression of 14-3-3a inhibits BBSV infection. In contrast, we found increased $\mathrm{CP}$ accumulation in leaves overexpressing 14-3-3a mutants that fail to interact with CP (Fig. 5a), suggesting a dominant-negative effect of these mutants on BBSV infection. We also transiently silenced 14-3-3a followed by infiltration with Agrobacterium harboring the BBSV infectious clone at $24 \mathrm{hpi}$. Western blotting with anti-CP or anti-14-3-3a antibodies showed that the accumulation of viral CPs was increased along with the downregulation of 14-3-3a expression (Fig. 5b). To further confirm the role of 14-3-3a in BBSV infection, we generated 14-3-3a overexpression (14-3-3a-OE) and knockdown (14-3-3a-KD) transgenic $N$. benthamiana plants. We then compared the symptoms of WT and transgenic N. benthamiana plants upon BBSV infection. The symptoms of BBSVinfected plants were arbitrarily divided into four grades based on the severity of symptoms on systemic leaves (Supplementary Fig. 8). When these transgenic plants were inoculated with BBSV virions, we found that a higher percentage of 14-3-3a-OE plants showed attenuated symptoms (grade I) and a lower percentage of plants showed severe disease symptoms (grade III) in the systemic leaves. In contrast, BBSV induced more severe symptoms in 14-3$3 a-\mathrm{KD}$ plants compared with that of the control WT plants 
a

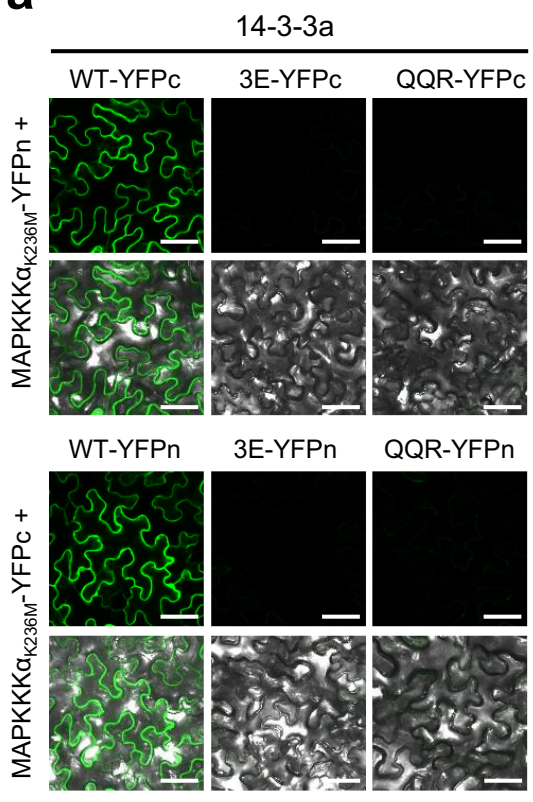

C

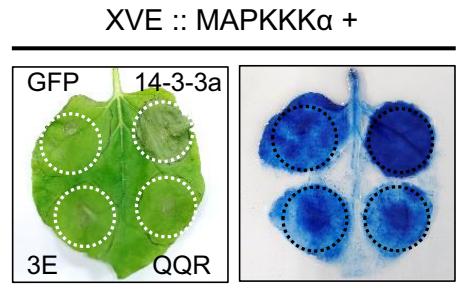

d

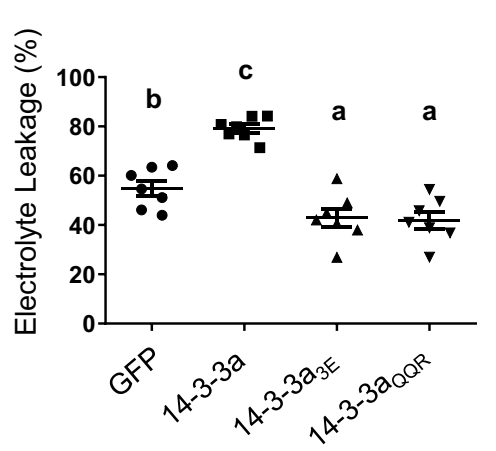

e

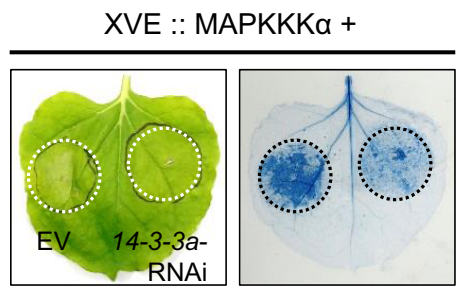

f

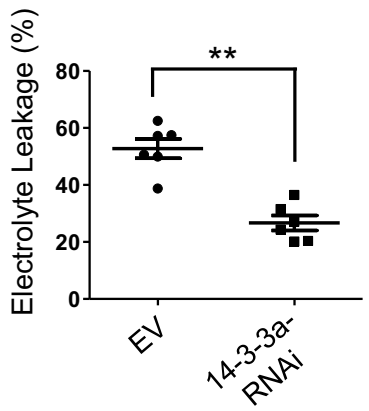

b

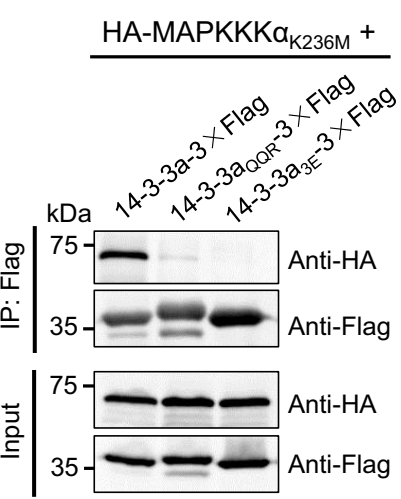

g

i
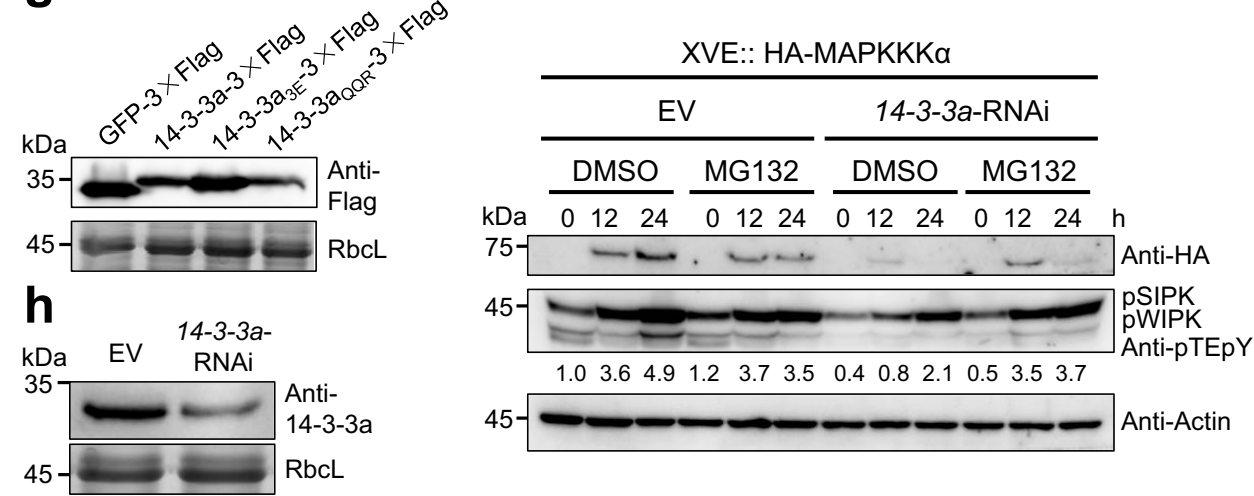

Fig. 4 14-3-3a positively regulates MAPKKK $\alpha$-induced cell death. a BiFC analysis of the interaction between wild-type or mutant 14-3-3a and MAPKKK $\alpha$. Combinations of different proteins were transiently expressed in $N$. benthamiana leaves. Confocal analysis was performed at 3 dpi. Representative results of at least three independent experiments are shown. Scale bars $=50 \mu \mathrm{m}$. b Co-IP analysis of the interaction between wild-type or mutant 14-3-3a and MAPKKK $\alpha_{K 236 \mathrm{M}}$. N. benthamiana leaves transiently expressing combination of different proteins were harvested at $3 \mathrm{dpi}$. Total proteins were immunoprecipitated with anti-Flag beads and detected by western blot with an anti-HA or anti-Flag antibody. The experiment was repeated three times with similar results. c Overexpression of 14-3-3a enhances MAPKKK $\alpha$-induced cell death. Indicated proteins together with HA-MAPKKK $\alpha$ controlled by an estradiol-inducible system were co-expressed in different leaf regions. $\beta$-estradiol was applied to the leaves $48 \mathrm{~h}$ after agroinfiltration. Leaves were stained by trypan blue and representative photographs were taken 3 days after estradiol treatment. $\mathbf{d}$ Quantification of cell death by measuring electrolyte leakage of leaf regions shown in panel (c). Error bars indicate \pm SD of the mean ( $n=7$ biologically independent plants). Different letters in the chart indicate statistically significant differences among different groups according to the one-way ANOVA analysis with Tukey's multiple comparison test $(P<0.05)$. e Knockdown of 14-3-3a eliminates MAPKKK $\alpha$-induced cell death. Agrobacterium containing hairpin 14-3-3a or the control empty vector was co-infiltrated with HA-MAPKKK $\alpha$ controlled by an estradiol-inducible system into the opposite halves of $N$. benthamiana leaves. $\beta$-estradiol was applied to the leaves $48 \mathrm{~h}$ after agroinfiltration. Leaves were stained by trypan blue and representative photographs were taken 3 days after estradiol treatment. $\mathbf{f}$ Quantification of cell death by measuring electrolyte leakage of leaves treated as described in (e). Error bars indicate \pm SD of the mean ( $n=6$ biologically independent plants). Asterisks indicate the significant difference $\left({ }^{\star \star} P=0.0024\right)$ based on one-sided paired Student's $t$ test. $\mathbf{g}$ Western blot analysis to confirm the expression of the GFP and 14-3-3a proteins shown in panel $\mathbf{c}$ with an anti-Flag antibody. $\mathbf{h}$ Western blot analysis to confirm the downregulation of $14-3-3 a$ at protein level shown in panel $\mathbf{e}$ with an anti-14-3-3a antibody. $\mathbf{i} 14-3-3 a$ is important for maintaining the stability of MAPKKK $\alpha$. Agrobacterium containing hairpin 14-3-3a or empty vector were co-infiltrated with HA-MAPKKK $\alpha$ controlled by an estradiol-inducible system into the leaves. In total, $30 \mu \mathrm{M} \beta$ estradiol with $50 \mu \mathrm{M}$ MG132 or DMSO (control) was infiltrated into the leaves $48 \mathrm{~h}$ after agroinfiltration. Samples were collected at $0,12,24 \mathrm{~h}$ after treatment with a chemical reagent, and subjected to western blot with an anti-HA or anti-pTEpY antibody. For panels $\mathbf{g}-\mathbf{i}$, the experiments were repeated three times with similar results. 

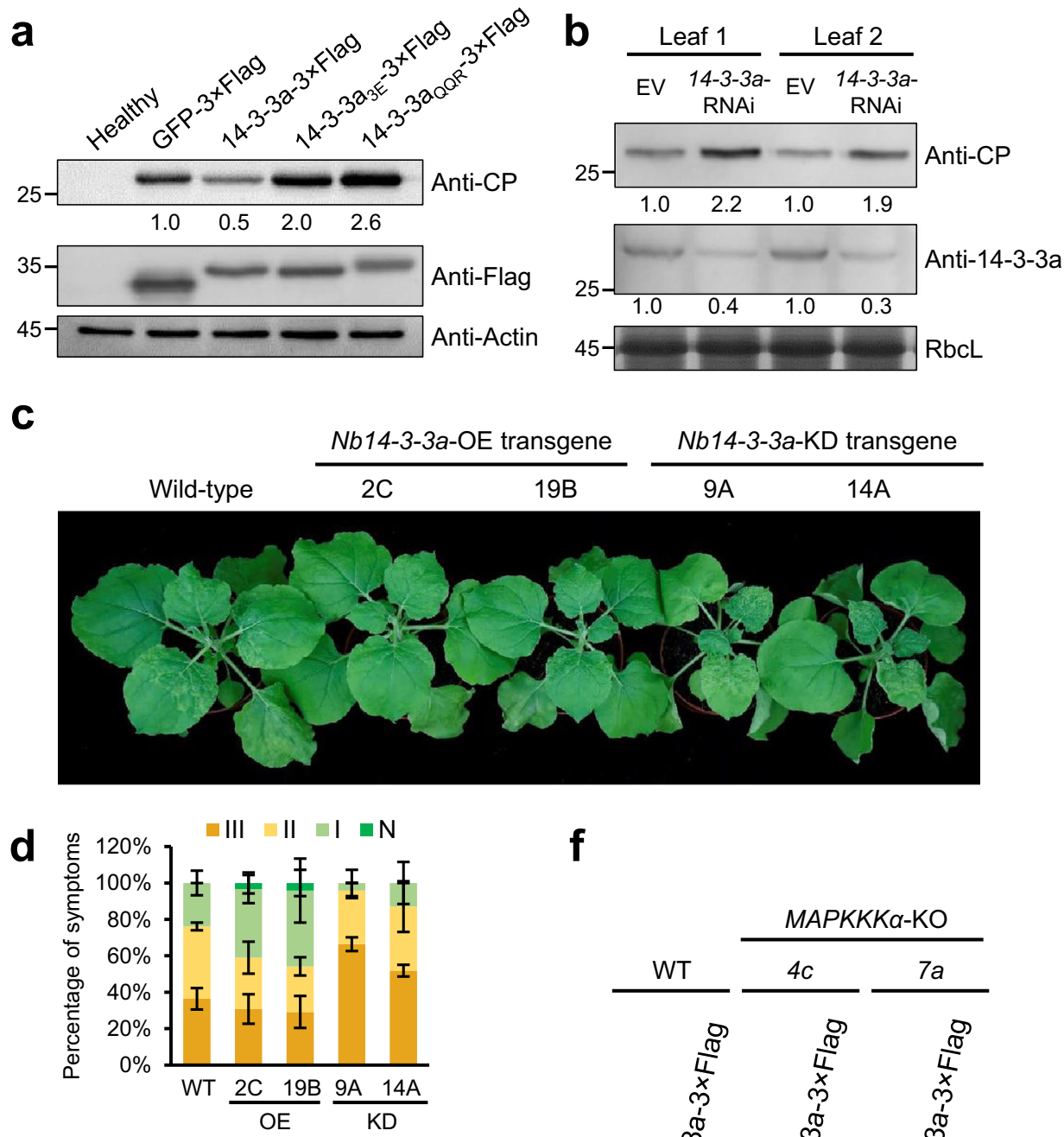

$\mathbf{e}$
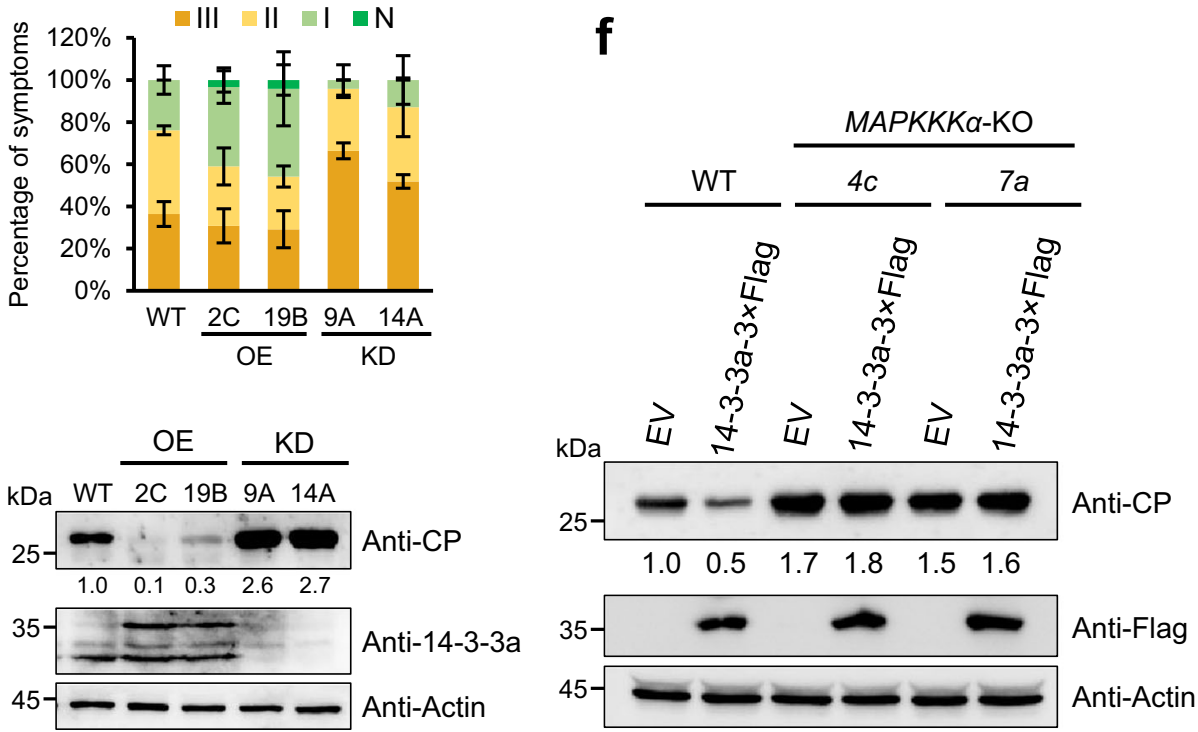

Fig. 5 Nb14-3-3a-mediated antiviral defense depends on the MAPKKK $\alpha$. a Overexpression of 14-3-3a inhibits BBSV infection. Agrobacterium containing indicated construct above the panel was infiltrated into $N$. benthamiana leaves followed by mechanical inoculation with $300 \mathrm{ng}$ BBSV virions $24 \mathrm{~h}$ later. Inoculated leaves were collected at $3 \mathrm{dpi}$ and analyzed by western blot analysis with an anti-CP or anti-Flag antibody. Actin served as the loading control. b Knockdown of Nb14-3-3a increases the accumulation of BBSV. The opposite halves of $\mathrm{N}$. benthamiana leaves were agroinfiltrated with 14-3-3a-RNAi construct and the control empty vector (EV). Agrobacterium carrying BBSV infection clone was infiltrated into the previously infiltrated regions $24 \mathrm{~h}$ later. Leaf samples from infiltrated regions were harvested at 3 dpi and subjected to western blot with an anti-CP or anti-14-3-3a antibody. CBB-stained RbcL served as the loading control. For panels $\mathbf{a}$ and $\mathbf{b}$, the experiments were repeated three times with similar results. $\mathbf{c}$ Phenotypes of BBSV-infected WT, 14-33a-OE, and 14-3-3a-KD plants. N. benthamiana leaves were inoculated with $100 \mathrm{ng}$ BBSV virions. Photographs were taken at 14 dpi and a representative result is shown. $\mathbf{d}$ The percentages of BBSV-infected wild-type (WT), 14-3-3a-OE, and 14-3-3a-KD plants with different disease symptom grades. Error bars indicate \pm SD of the mean three independent experiments $(n=3)$ with at least six plants in each experiment. e Western blot analysis of BBSV CP levels in the indicated plants using an anti-CP or anti-14-3-3a antibody. Actin served as the loading control. $\mathbf{f}$ Western blot analysis of BBSV CP levels in the infiltrated leaves of WT or NbMAPKKK $\alpha-K O$ plants using an anti-CP or anti-Flag antibody. Actin served as the loading control. For panels $\mathbf{e}$ and $\mathbf{f}$, the experiments were repeated three times with similar results.

(Fig. 5c, d). Consistently, BBSV CP accumulated to a significantly lower level in 14-3-3a-OE plants, whereas CP accumulation was increased more than twice in $14-3-3 a-\mathrm{KD}$ plants in comparison with the non-transgenic plants (Fig. 5e). Together, these results demonstrate that 14-3-3a plays an antiviral role in BBSV infection.
Based on the data presented above, we reasoned that 14-3-3amediated defense against BBSV might depend on MAPKKKa. To test this hypothesis, we overexpressed 14-3-3a in WT and $M A P K K K \alpha-\mathrm{KO}$ plants, and performed BBSV infection assay. Western blot analysis showed that overexpression of 14-3-3a in 
$M A P K K K \alpha-\mathrm{KO}$ plants failed to impair the BBSV infection based on the $\mathrm{CP}$ accumulation, in contrast to that of the WT plants (Fig. 5f). These results suggest that 14-3-3a positively regulates antiviral defense in a MAPKKKa-dependent manner.

CP suppresses the MAPKKKa-mediated cell-death signaling by targeting Nb14-3-3a. BBSV CP is divided into two regions: a $\mathrm{N}$-terminal region responsible for RNA binding and nuclear localization $^{45,46}$, and a shell domain ${ }^{47}$. To determine the region of $\mathrm{CP}$ protein that is important for its binding to 14-3-3a, we constructed $\mathrm{N}$-terminal or $\mathrm{C}$-terminal truncated $\mathrm{CP}$ mutants respectively (Fig. 6a), and tested their interactions with 14-3-3a by BiFC assay. The result showed that $\mathrm{CP}_{46-232}$ retains the ability to interact with 14-3-3a, whereas $\mathrm{CP}_{1-187}$ was unable to interact with 14-3-3a (Fig. 6b). The expression of proteins was confirmed by western blot analysis (Supplementary Fig. 3e). These results indicate that the C-terminal region between amino acids 188 and 232 is required for $\mathrm{CP}$ interaction with 14-3-3a. By aligning CP sequences of BBSV and TNV- $\mathrm{D}^{\mathrm{H}}$, we found a motif in this region, which is similar to a conventional 14-3-3-binding motif ( $\mathrm{Rxx}[\mathrm{pS} /$ $\mathrm{pT}] \mathrm{xP})^{48}$. Intriguingly, this motif in BBSV CP contains tyrosine (Y) instead of $\mathrm{S} / \mathrm{T}$ and $\mathrm{TNV}-\mathrm{D}^{\mathrm{H}}$ contains phenylalanine $(\mathrm{F})$ (Fig. 6c). The $\mathrm{Y}$ and $\mathrm{F}$ amino acids are structurally similar, implying that the phosphorylation of the 14-3-3-binding motif in BBSV CP may not be required for its binding to 14-3-3a and the maintenance of the structure may be critical for its binding. To test this hypothesis, we mutated Y194 in BBSV CP into F and alanine (A) and tested their binding abilities to 14-3-3a. BiFC, Co-IP, and GST pull-down assays showed that $\mathrm{CP}_{\mathrm{Y} 194 \mathrm{~F}}$ mutant retains the ability to interact with $14-3-3 a$, whereas $\mathrm{CP}_{\mathrm{Y} 194 \mathrm{~A}}$ mutant did not (Fig. 6d-f). The expression of proteins in BiFC assay was confirmed by western blot analysis (Supplementary Fig. 3e). Together, these data indicate that the conformation but not the phosphorylation state of Y194 of CP is important for its interaction with 14-3-3a.

To investigate whether CP suppressed MAPKKKa-mediated cell death by binding to 14-3-3a, wild-type or mutant CPs were co-expressed with estradiol-induced HA-MAPKKKa. Trypan blue staining and electrolyte-leakage assays showed that leaf tissues expressing $\mathrm{CP}$ and $\mathrm{CP}_{\mathrm{Y} 194 \mathrm{~F}}$, but not $\mathrm{CP}_{\mathrm{Y} 194 \mathrm{~A}}$, exhibited reduced cell death induced by MAPKKKa compared with the EV control (Fig. 7a, b). The expression of CP proteins was confirmed by western blot analysis (Fig. 7c). Since $\mathrm{CP}_{\mathrm{Y} 194 \mathrm{~A}}$ barely interact with 14-3-3a (Fig. 6d-f), we conclude that inhibition of MAPKKKa-induced cell death by viral CP is dependent on its interaction with 14-3-3a.

To investigate the molecular basis underpinning the CP inhibition of MAPKKKa-induced cell death, we detected the levels of MAPKKKa proteins and activation of MAPKs (phosphorylation of SIPK and WIPK) at different time points after induction of MAPKKKa expression in the presence of CP or $\mathrm{CP}_{\mathrm{Y} 194 \mathrm{~A}}$. Western blot analysis showed that, compared with EV control, the abundance of HA-MAPKKKa was decreased in the leaves expressing $\mathrm{CP}$, but showed no obvious changes in the leaves expressing $\mathrm{CP}_{\mathrm{Y} 194 \mathrm{~A}}$ (Fig. $7 \mathrm{~d}$ ). Consistently, the levels of SIPK and WIPK phosphorylation were also decreased in leaves expressing CP (Fig. 7d). To determine whether CP was able to impair the enhancement of 14-3-3a on MAPKKKa-mediated signaling, we conducted a similar assay in 14-3-3a-OE transgenic $N$. benthamiana plants. Levels of both MAPKKKa proteins and MAPKs phosphorylation were decreased in the leaves expressing $\mathrm{CP}$ (Fig. 7e). We also generated stable N. benthamiana transgenic lines overexpressing CP. Compared with the WT plants, two independent $N$. benthamiana plants stably overexpressing CP showed a decreased abundance of MAPKKKa and reduced phosphorylation of MAPKs after induction of MAPKKKa expression (Fig. 7f). Together, these results indicate that CP suppresses the activation of MAPKs by reducing the abundance of MAPKKKa.

It has been previously shown that the $\mathrm{CP}$ of another RNA virus, potato virus $\mathrm{X}$ (PVX) accumulate to a higher level in $N b M A P K K K \alpha$-silenced $N$. benthamiana plants ${ }^{49}$. Therefore, we tested whether BBSV CP mediated reduction of MAPKKKa could lead to enhanced PVX infection. For this, we engineered BBSV $\mathrm{CP}$ or $\mathrm{CP}_{\mathrm{Y} 194 \mathrm{~A}}$ into PVX-based vector and agroinfiltrated into $N$. benthamiana. The symptoms caused by PVX-BBSV-CP were more severe than that of either PVX-BBSV-CP ${ }_{\mathrm{Y} 194 \mathrm{~A}}$ or PVX-GFP (Fig. 7g). Consistently, the accumulations of both PVX and BBSV CP in the systemic leaves of PVX-BBSV-CP-infected $N$. benthamiana were higher than that in PVX-BBSV-CP ${ }_{\mathrm{Y} 194 \mathrm{~A}}$ or PVX-GFP-infected plants (Fig. 7h). These results further revealed that BBSV CP has the ability to inhibit MAPKKKa-mediated antiviral immunity.

To further explore the biological significance of the CP-14-3-3a interaction on MAPKKKa-mediated defense against BBSV infection, we generated BBSV mutant by replacing $\mathrm{CP}$ with $\mathrm{CP}_{\mathrm{Y} 194 \mathrm{~A}}\left(\mathrm{BBSV}_{\mathrm{Y} 194 \mathrm{~A}}\right)$ and inoculated them onto WT or $M A P K K K \alpha-K O$ plants. We observed cell-death phenotype on the leaves of WT plants inoculated with BBSV $_{\mathrm{Y} 194 \mathrm{~A}}$ at $2 \mathrm{dpi}$ but not for the leaves inoculated with WT-BBSV (Supplementary Fig. 9a). In contrast, neither BBSV nor BBSV $_{\mathrm{Y} 194 \mathrm{~A}}$ induced celldeath phenotype on the inoculated leaves of $M A P K K K \alpha-\mathrm{KO}$ plants (Supplementary Fig. 9a), indicating that the $\mathrm{BBSV}_{\mathrm{Y}_{194 \mathrm{~A}^{-}}}$ induced cell death depends on the MAPKKKa. Consistent with this, leaves inoculated with BBSV $_{\mathrm{Y} 194 \mathrm{~A}}$ showed a lower level of CP accumulation compared with BBSV, and knocking out of the NbMAPKKK $\alpha$ gene partially rescues the accumulation level of BBSV $_{\mathrm{Y} 194 \mathrm{~A}}$ (Supplementary Fig. 9b). We did not observe the systemic infection of $\mathrm{BBSV}_{\mathrm{Y} 194 \mathrm{~A}}$ in either WT or MAPKKK $\alpha-\mathrm{KO}$ plants (Supplementary Fig. 9b, c), suggesting the Y194 in CP is critical for BBSV systemic infection. Since the Y194A mutation eliminates the interaction of $\mathrm{CP}$ with 14-3-3a, these results indicate that the interaction of CP with 14-3-3a is essential for suppressing MAPKKKa-mediated cell death during BBSV infection.

CP competitively interferes with the MAPKKKa binding to 143-3a. Given that both CP and MAPKKKa interact with 14-3-3a but CP does not interact with MAPKKKa (Figs. 3 and $4 \mathrm{a}$, b and Supplementary Fig. 4), we wonder whether CP interferes with the interaction of MAPKKKa with 14-3-3a. To test this hypothesis, we performed a competitive Co-IP assay. Agrobacterium containing 14-3-3a-3 $\times$ Flag and HA-MAPKKKa ${ }_{\mathrm{K} 236 \mathrm{M}}$ expression cassette were co-infiltrated into the $N$. benthamiana leaves. Leaf homogenates were prepared and mixed with E. coli-expressed His-tagged CP proteins. After incubation for $40 \mathrm{~min}$, the homogenates were precipitated with anti-Flag beads, and the eluates were then examined by western blot. The results showed that the association between 14-3-3a-3×Flag and HA-MAPKKKa $\alpha_{\mathrm{K} 236 \mathrm{M}}$ was reduced with the addition of increasing amounts of $E$. coliexpressed His-tagged CP (His-CP). However, $\mathrm{CP}_{\mathrm{Y} 194 \mathrm{~A}}$ mutant protein, which barely interacts with 14-3-3a, had little effect on the interaction of $14-3-3 \mathrm{a}-3 \times$ Flag with $\mathrm{HA}-\mathrm{MAPKKKa_{ \textrm {K } 2 3 6 \mathrm { M } }}$ (Fig. 8a). Furthermore, we performed GFP competitive pull-down assay. Because E. coli-expressed MAPKKKa was insoluble, GFPfused MAPKKKa $\mathrm{K}_{\mathrm{K} 236 \mathrm{M}}$ was expressed in $N$. benthamiana followed by purification with GFP-Trap beads. An excessive amount of E. coli-expressed His-14-3-3a was used to saturate the beads, and the supernatant was removed. With the addition of an increasing amount of E. coli-expressed His-CP to the above 
a

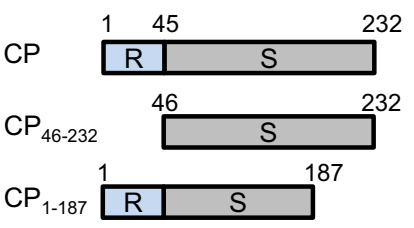

b

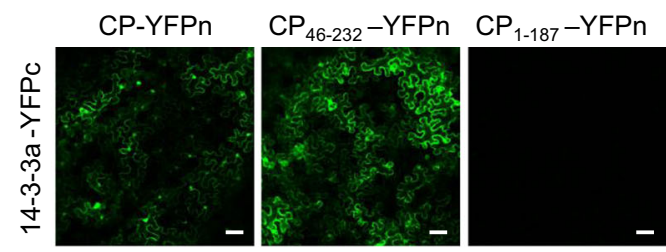

C

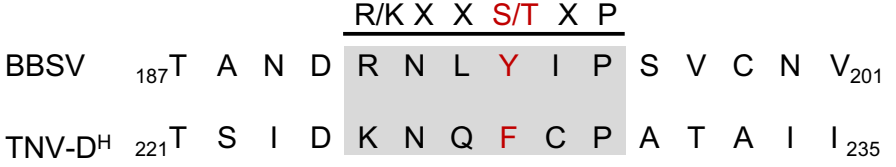

d
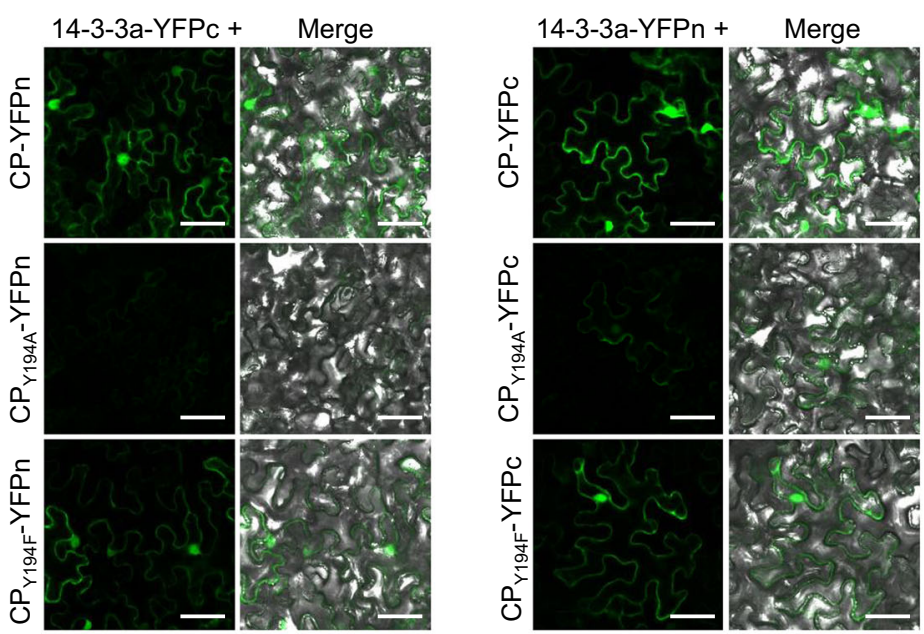

e
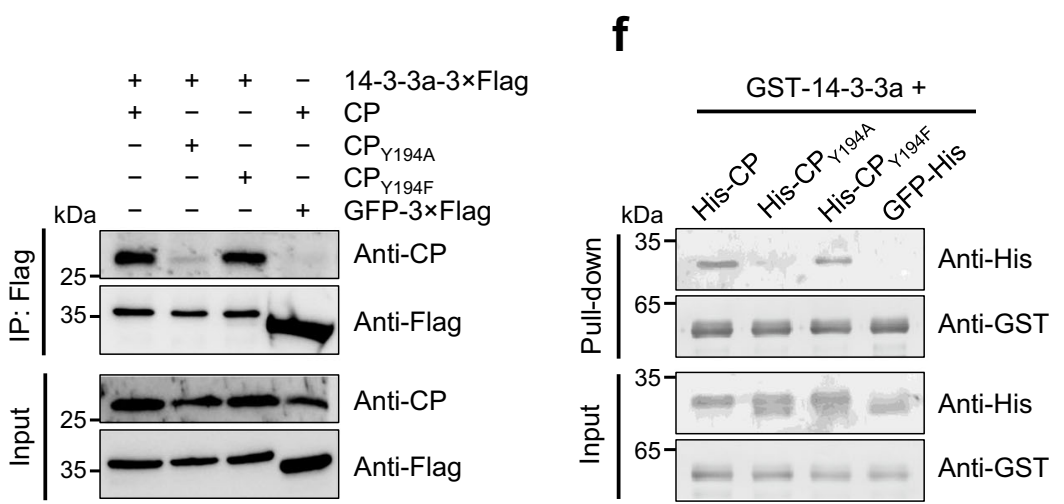

Fig. 6 Determination of key amino acids that are responsible for CP-14-3-3a interaction. a Schematic representation of CP truncated mutants used for $\mathrm{BiFC}$ assays. $\mathbf{b} \mathrm{BiFC}$ analysis of regions within CP that interacted with 14-3-3a. Wild-type or truncated CP mutants fused to N-terminus of YFP and 14-3-3a fused to $\mathrm{C}$-terminus were transiently co-expressed in $\mathrm{N}$. benthamiana leaves. Confocal analysis was performed at 3 dpi. Representative results of at least three independent experiments are shown. Scale bars $=50 \mu \mathrm{m}$. c Multiple sequence alignment of the C-terminus of CPs from Betanecroviruses. The 14-33-binding-like motif is shaded in gray, and the putative 14-3-3-binding site is highlighted in red. $\mathbf{d}$ BiFC analysis of the interaction between wild-type or mutant CP and 14-3-3a. Wild-type or mutant CP and 14-3-3a fused to N or C-terminus of YFP were transiently co-expressed in N. benthamiana leaves. Confocal analysis was performed at $3 \mathrm{dpi}$. Representative results of at least three independent experiments are shown. Scale bars $=50 \mu \mathrm{m}$. e Co-IP analysis of the interaction between wild-type or mutant CP and 14-3-3a. N. benthamiana leaves transiently expressing combinations of different proteins were harvested at $3 \mathrm{dpi}$. Total proteins were immunoprecipitated with anti-Flag beads and detected by western blot with an anti-CP or anti-Flag antibody. f GST pull-down assay to detect the interaction between wild-type or mutant CP and 14-3-3a. Purified His-tagged CP or its derivatives was incubated with GST-14-3-3a or GST protein. His-GFP protein served as the negative control. After incubation with glutathione-Sepharose beads, the pull-down products were analyzed by western blot with an anti-His or anti-GST antibody. For panels $\mathbf{e}$ and $\mathbf{f}$, the experiments were repeated three times with similar results. 
a
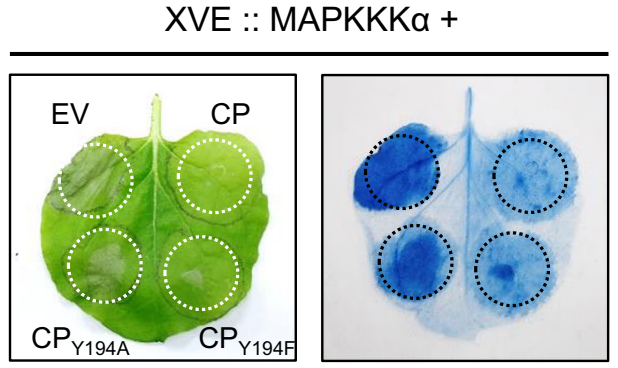

d

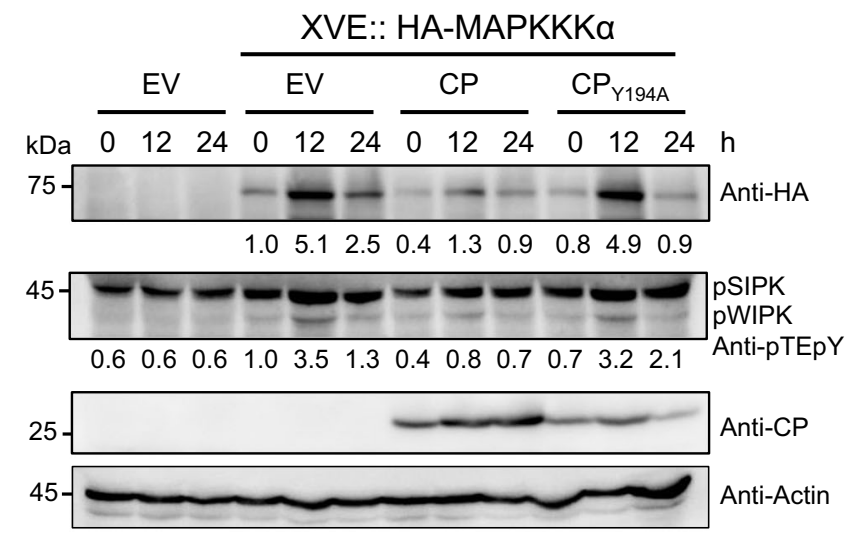

$\mathbf{f}$

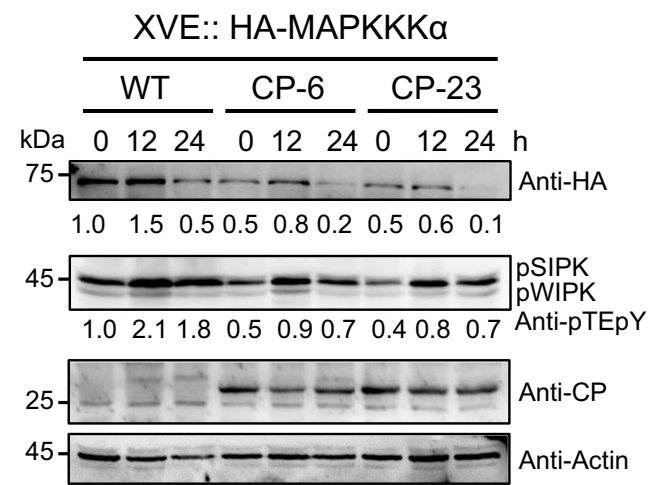

b

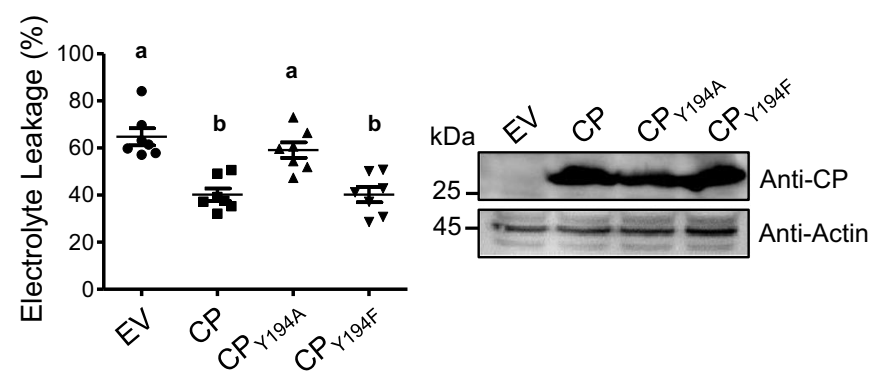

e

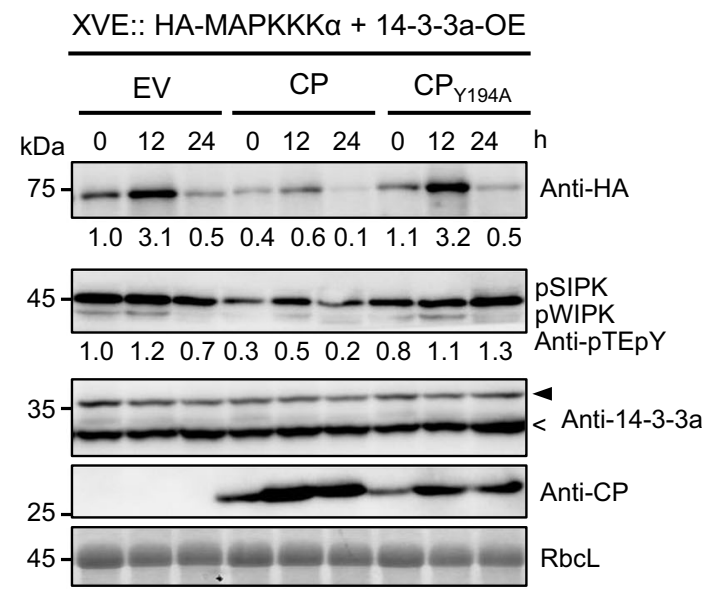

h

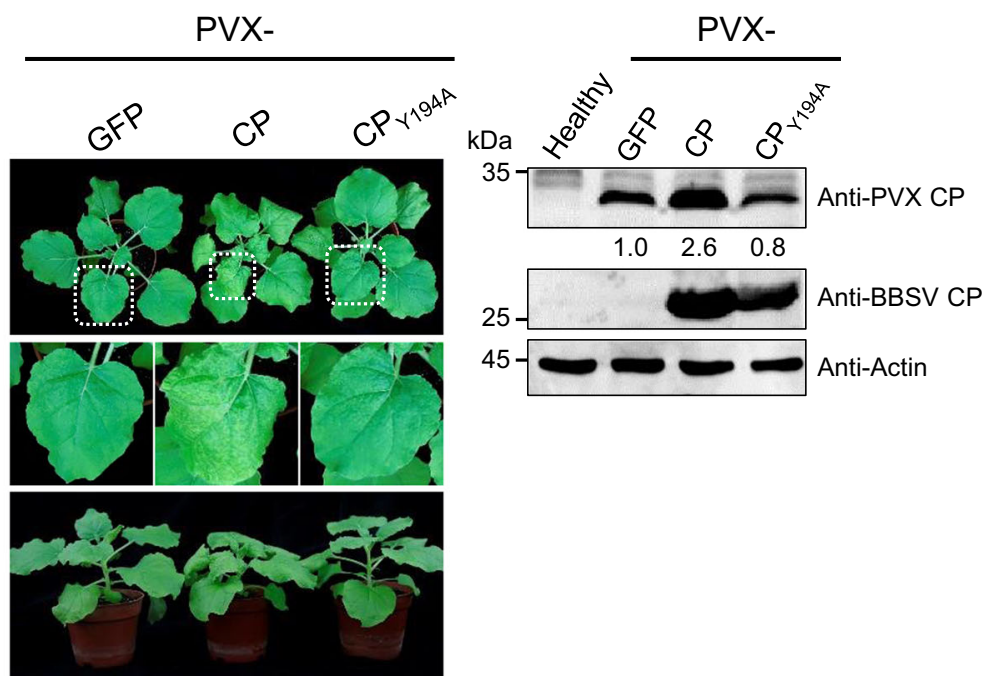

GFP-Trap beads, more and more His-14-3-3a was pulled off from the beads concomitant with increased levels of His-14-3-3a in the supernatant (Fig. 8b). These data indicate that CP competitively interferes the interaction between MAPKKKa and 14-3-3a, leading to a decrease in the abundance of MAPKKKa (Fig. 8c).

Perturbation of 14-3-3a-MAPKKKa functional module by the CP may be a common strategy employed by necroviruses. Sequence alignments showed that the 14-3-3a binding-like motif is conserved in the CPs of alphanecrovirus and betanecrovirus (Supplementary Fig. 10), suggesting that the perturbation of 14-33a-MAPKKKa functional module by CP may also be employed by other necroviruses. To test this hypothesis, the conserved 14-3- 3a binding site $\mathrm{F}^{236}$ in the $\mathrm{CP}$ of Tobacco necrosis virus-A (TNV$\mathrm{A}^{\mathrm{C}}$, alphanecrovirus) and $\mathrm{F}^{228}$ in the $\mathrm{CP}$ of $\mathrm{TNV}-\mathrm{D}^{\mathrm{H}}$ (betanecrovirus) were mutated to alanine. BiFC assay showed that coexpression of 14-3-3a with wild-type TNV-A ${ }^{\mathrm{C}}$ and $\mathrm{TNV}-\mathrm{D}^{\mathrm{H}} \mathrm{CPs}$, but not mutant $\mathrm{CPs}$, resulted in the reconstitution of fluorescence signals (Fig. 9a, b). Expression of the test proteins was confirmed by western blot analysis (Supplementary Fig. 3f). These results indicate that both TNV-A $\mathrm{A}^{\mathrm{C}}$ and TNV-D $\mathrm{H}$ CPs interact with 14-3$3 \mathrm{a}$, and the amino acids $\mathrm{F}^{236}$ or $\mathrm{F}^{228}$ within the CPs are crucial for their interaction with 14-3-3a.

To examine the effect of TNV-AC and TNV-D $\mathrm{D}^{\mathrm{H}} \mathrm{CPs}$ on MAPKKKa-induced cell death, wild-type or mutant CPs was coexpressed with HA-MAPKKKa controlled by an estradiol- 
Fig. 7 CP suppresses the MAPKKKo-mediated immune signaling by targeting Nb14-3-3a. a Interaction with 14-3-3a is required for CP to inhibit MAPKKK $\alpha$-induced cell death. Agrobacterium carrying wild-type CP or its variants was co-infiltrated with Agrobacterium containing HA-MAPKKK $\alpha$ controlled by an estradiol-inducible system into different leaf regions. $\beta$-estradiol was used to induce protein expression $48 \mathrm{~h}$ after agroinfiltration. Leaves were stained by trypan blue and representative photographs were taken three days after estradiol treatment. $\mathbf{b}$ Quantification of cell death by measuring electrolyte leakage of leaf regions shown in (a). Error bars indicate \pm SD of the mean ( $n=6$ biologically independent plants). Different letters in the chart denote statistically significant differences among different groups according to the one-way ANOVA analysis with Tukey's multiple comparison test $(P<0.05)$. c Western blot analysis to confirm the expression of the CP or its variants with an anti-CP antibody. $\mathbf{d} C P$ suppresses MAPKKK $\alpha$ protein accumulation and MAPK activation in WT N. benthamiana. Agrobacterium carrying CP, CP Agrobacterium containing HA-MAPKKK $\alpha$ controlled by an estradiol-inducible system into leaves. $30 \mu \mathrm{M} \beta$-estradiol was infiltrated into the leaves $48 \mathrm{~h}$ after agroinfiltration. Samples were collected at 0, 12, $24 \mathrm{~h}$ after $\beta$-estradiol treatment and subjected to western blot analysis with different antibodies indicated on the right. Actin served as the loading control. e CP suppresses MAPKKK $\alpha$ protein accumulation and MAPK activation in 14-3-3a-OE transgenic N. benthamiana. Agrobacterium carrying CP, $\mathrm{CP}_{\mathrm{Y} 194 \mathrm{~A}}$ or empty vector was co-infiltrated with Agrobacterium containing HA-MAPKKK $\alpha$ controlled by an estradiol-inducible system into leaves. In total, $30 \mu \mathrm{M} \beta$-estradiol was applied to the leaves $48 \mathrm{~h}$ after agroinfiltration. Samples were collected at $0,12,24 \mathrm{~h}$ after $\beta$-estradiol treatment and subjected to western blot analysis with different antibodies indicated on the right. CBB-stained RbcL served as the loading control. $\mathbf{f}$ CP-transgenic $N$. benthamiana exhibited reduced accumulation of HA-MAPKKK $\alpha$ protein and MAPK phosphorylation compared with WT plants. Agrobacterium carrying HA-MAPKKK $\alpha$ controlled by an estradiol-inducible system was infiltrated into leaves. In all, $30 \mu \mathrm{M} \beta$-estradiol was applied to the leaves $48 \mathrm{~h}$ after agroinfiltration. Samples were collected at $0,12,24 \mathrm{~h}$ after $\beta$-estradiol treatment and subjected to western blot with different antibodies indicated on the right. Actin served as the loading control. For panels c-f, the experiments were repeated three times with similar results. $\mathbf{g}$ Symptom observation of engineered PVX-inoculated N. benthamiana plants. Agrobacterium carrying engineered PVX infection clones were infiltrated into two leaves of each plant. Representative photographs were taken at $6 \mathrm{dpi}$. $\mathbf{h}$ Western blot analysis of viral CP in the systemic leaves shown in panel $g$ by using antiPVX-CP or anti-BBSV CP antibody. Actin served as the loading control. The experiment was repeated three times with similar results.

inducible system. Trypan blue staining and the electrolyte-leakage assays showed that compared with the EV control, MAPKKKainduced cell death was significantly decreased in leaf tissues expressing wild-type CPs, but not mutant CPs (Fig. 9c-f). Consistently, the levels of MAPKKKa proteins and downstream MAPK phosphorylation level were decreased in the leaves expressing wild-type CPs, but not mutant CPs, compared with the EV control (Fig. 9g, h).

We also investigated whether 14-3-3a and MAPKKKa play antiviral roles in TNV-A $\mathrm{C}^{\mathrm{C}}$ and $\mathrm{TNV}-\mathrm{D}^{\mathrm{H}}$ infection. 14-3-3a-OE and $M A P K K K \alpha-\mathrm{KO}$ plants were inoculated with $\mathrm{TNV}-\mathrm{A}^{\mathrm{C}}$ or $\mathrm{TNV}-\mathrm{D}^{\mathrm{H}}$, respectively. TNV-A $\mathrm{A}^{\mathrm{C}}$ and $\mathrm{TNV}-\mathrm{D}^{\mathrm{H}}$ caused more severe symptoms in $M A P K K K \alpha-\mathrm{KO}$ plants than WT plants (Fig. 9i, j). Western blot and RT-qPCR analysis showed that both TNV-AC and TNV-D $\mathrm{D}^{\mathrm{H}}$ accumulation was increased in $M A P K K K \alpha-K O$ plants (Fig. 9k, l) and significantly decreased in 14-3-3a-OE plants (Supplementary Fig. 11). These findings indicate that other necroviruses may utilize the same strategy as that of BBSV to counteract MAPKKKa-mediated antiviral immunity.

\section{Discussion}

MAPK cascades play a central role in defense signaling against pathogens ${ }^{20}$. In animals, both DNA and RNA viruses are known to induce the MAPK cascades ${ }^{50,51}$. They utilize and fine-tune MAPK cascades to promote viral replication ${ }^{52,53}$. However, the relationship between MAPK cascades and plant viruses remains understudied. Here, we show that MAPKKKa plays an antiviral role. Our findings showed that the MAPK cascade is activated during the early stage of BBSV infection as a defense mechanism. Consistent with this, downregulation of MAPKKKa, as well as the downstream MAPKs, enhanced the accumulation of BBSV. Likewise, MAPK cascades are also reported to be activated in tomato yellow leaf curl China virus (TYLCCNV)-infected $N$. benthamiana $^{36}$ and TMV-infected tobacco plants expressing $\mathrm{R}$ protein $\mathrm{N}^{28}$. Knockout of NbSIPKK and NbMPK4 also enhances TYLCCNV infection and the suppression of NtMEK2-SIPK/ WIPK cascade compromises $N$-mediated resistance against TMV. These studies, together with the data shown here indicate the negative effect of MAPK cascades in plant-virus infection. Our time-course analysis of the NbMAPKKK $\alpha$ mRNA levels during BBSV infection showed no significant change in NbMAPKKK $\alpha$ expression (Supplementary Fig. 12a), consistent with the RNAseq data (Supplementary data 4). Although phosphorylation levels of SIPK and WIPK were significantly increased in response to BBSV infection (Fig. 1h, i), the protein levels of SIPK and WIPK were also not altered during BBSV infection (Supplementary Fig. 12c). These results suggest that BBSV-induced activation of MAPK signaling pathway is through modulation of the phosphorylation status of MAPKKKa-MEK2-SIPK/WIPK components but not through the increased protein expression.

Although it has been reported that MAPK cascades play an important role in plant defense against a variety of pathogens ${ }^{18}$, the mechanism underlying MAPK-mediated defense against plant-virus infection remains largely unclear. Here, we performed RNA-seq analysis to reveal that the expression of a large number of genes were transcriptionally regulated in response to BBSV infection, and some of these genes are specifically regulated through MAPKKKa (Fig. 2). For example, PR1A (a salicylic acid (SA)-responsive gene), ERF1B (a transcription factor that is involved in ethylene signaling), and HIR1 (specifically associated with the HR cell death) are all reported to be regulated during plant defense against virus ${ }^{40,54,55}$. Moreover, the SA pathway, ethylene pathway, and HR cell death are reported to cross-talk with each other and also with MAPK signaling pathway ${ }^{26,56-58}$. Hence, our results demonstrated that MAPKKKa plays an antiviral role by activating MAPK signaling and inducing downstream defense-related gene expression, which provides a global insight into the mechanisms underlying the MAPKKKa-mediated antiviral immunity. Nevertheless, more details on how these genes perceive the MAPK signaling and induce antiviral response needs further investigation. Besides, how viruses activate MAPK cascades is a remaining gap to be addressed in the future. It is likely that intracellular or extracellular receptors recognize some conserved structures such as the virions, viral ribonucleoprotein complexes, or viral-derived dsRNAs to initiate innate immune signaling ${ }^{59}$.

Although the activation of MAPK signaling has some effect on BBSV infection, it is not sufficient to block virus infection suggesting that BBSV may have evolved a strategy to suppress MAPK signaling. Our data showed that BBSV CP is responsible for counteracting MAPKKKa-mediated antiviral defense. Interestingly, unlike Pseudomonas bacterial effectors HopF2, HopAI1, and AvrRpt2, or the $\beta \mathrm{C} 1$ encoded by a satellite associated with a 
a

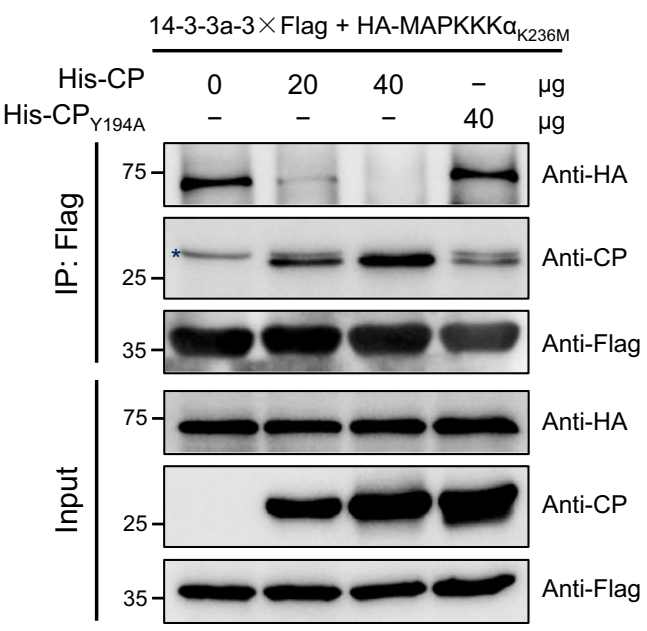

b

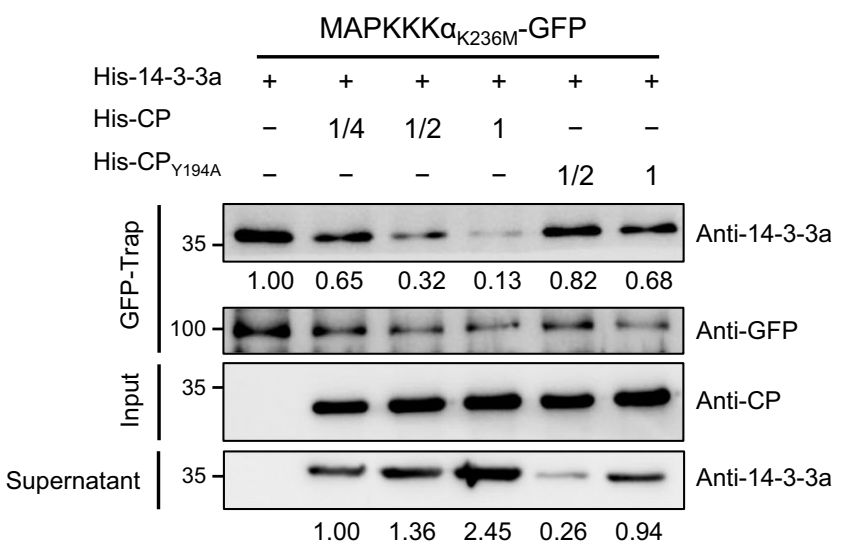

C

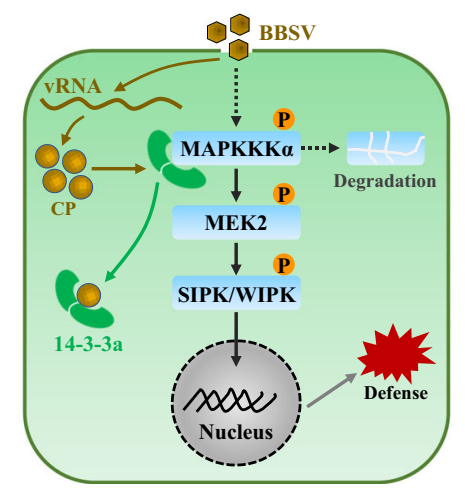

DNA virus that directly interacts with MAPKs and inactivates them to compromise defense responses ${ }^{33-36}$, BBSV CP does not interact with MAPKKKa. Instead, it interacts with 14-3-3a to modulate MAPKKKa-mediated antiviral immunity.

The 14-3-3 proteins are small acidic proteins $(\sim 30 \mathrm{kDa})$ that are highly conserved in eukaryotes ${ }^{60,61} 14-3-3$ proteins play important roles in signal transduction pathways to regulate diverse biological processes, such as cell division, primary metabolism, biotic and abiotic stress responses by interacting with various proteins in both plants and animals ${ }^{62-64}$. Accumulating evidence indicates that 14-3-3 proteins are involved in plant immunity ${ }^{41,42,65}$. 14-3-3 proteins interact with various signaling components of the plant immune system and modulate their activities, such as NADPH oxidase NtrbohD in N. tabacum ${ }^{66}$,
Fig. 8 CP interferes with the MAPKKKo interaction with 14-3-3a in a dose-dependent manner. a Competitive Co-IP assay. His-CP and His$\mathrm{CP}_{\mathrm{Y} 194 \mathrm{~A}}$ were purified from E. coli. 14-3-3a-3×Flag and HA-MAPKKK $\alpha_{K 236 \mathrm{M}}$ were co-expressed in $N$. benthamiana leaves and immunoprecipitated with anti-Flag beads. Anti-Flag beads with 14-3-3a-3×Flag and HA-

MAPKKK $\alpha_{K 236 \mathrm{M}}$ proteins was incubated with increasing amounts of His-CP protein $(0,20$, and $40 \mu \mathrm{g})$ or His-CP $\mathrm{CP}_{194 \mathrm{~A}}(40 \mu \mathrm{g})$. Input and IP proteins were analyzed by western blot with different antibodies indicated on the right. Asterisk indicates nonspecific bands. The experiment was repeated three times with similar results. $\mathbf{b}$ Competitive pull-down assay. MAPKKK $\alpha_{K 236 M}$-GFP was expressed in $N$. benthamiana leaves and immunoprecipitated with GFP-Trap agarose. After removing the supernatant, GFP-Trap agarose was incubated with E. coli-expressed His14-3-3a followed by removal of the supernatant. GFP-Trap agarose was incubated with a serial dilution of His-CP or His-CP ${ }_{Y 194 A}(1,1 / 2,1 / 4)$. The resultant agarose was analyzed by western blot with different antibodies indicated on the right. The experiment was repeated three times with similar results. c A proposed model for CP-Nb14-3-3a-MAPKKK $\alpha$ functional module in plant-virus interaction. Virus infection leads to the activation of the MAPK cascade-mediated antiviral defense. In turn, viral CP disturbs the interaction between 14-3-3a and MAPKKK $\alpha$, resulting in the degradation of MAPKKK $\alpha$ and the attenuation of antiviral response.

plasma membrane $\mathrm{H}^{+}$-ATPase in maize and Arabidopsis ${ }^{67}, \mathrm{R}$ protein RPW8.2 in Arabidopsis 68 , and MAPKKKa in tomato ${ }^{69}$. Although these studies unveil the important roles of 14-3-3 proteins in plant defense to nonviral pathogens, their roles in plant virus infection remain unexplored. Our findings described here, for the first time, revealed that 14-3-3a protein plays an antiviral role. Although we cannot rule out the possibility that other 14-3-3 isoforms may also participate in the plant immune response, our results indicate that 14-3-3a is at least one of the key regulators.

In animals, 14-3-3 interacts with and activates two MAPKKKs, Raf- 1 and MEKK $3^{70,71}$. In plants, ZmMPK6 is reported to interact with a maize 14-3-3 protein GF14-6 ${ }^{72}$. SIMAPKKKa is reported to interact with a tomato 14-3-3 protein TFT7 ${ }^{69}$. These results prompted us to test whether NbMAPKKKa could interact with 14-3-3a in $N$. benthamiana. Our results confirmed their interaction and revealed that 14-3-3a is required for NbMAPKKKa-mediated cell death in $N$. benthamiana, which is in accordance with the positive regulation of SIMAPKKKa by TFT7 in tomato ${ }^{69}$. Our results also showed that 14-3-3a could protect the MAPKKKa from ubiquitination-mediated degradation (Fig. 4i). Genetic analysis using $M A P K K K \alpha-K O$ plants indicated that 14-3-3a participate in MAPKKKa-mediated defense against BBSV infection. As a counter-defensive strategy, BBSV uses its CP to suppress MAPKKKa-mediated defense by directly interacting with 14-3-3a that reduces the MAPKKKa accumulation. Previous studies also showed that downregulation of MAPKKKa expression increases the accumulation of PVX in $N$. benthamiana ${ }^{49}$. Interestingly, expression of BBSV CP in the PVX infectious clone resulted in enhanced accumulation of PVX and symptoms, further supporting the BBSV CP suppression of MAPKKKa-mediated plant defense. We also performed a timecourse analysis of the Nb14-3-3a expression during BBSV infection and found no significant changes in the Nb14-3-3a expression levels (Supplementary Fig. 12b, c), consistent with the RNAseq data (Supplementary Data 5). Considering that the Nb14-33a-mediated antiviral defense depends on the MAPKKKa (Fig. 5) and the relatively high abundance of the endogenous plant 14-3-3 proteins (Supplementary Fig. 12c), we speculate that the endogenous level of 14-3-3 might be sufficient to activate MAPK signaling. 
a

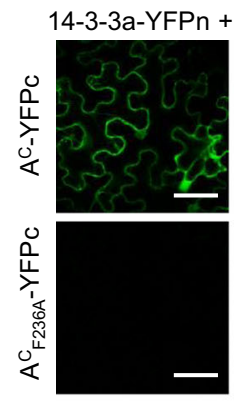

C

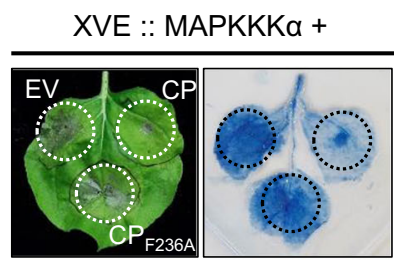

14-3-3a-YFPc +

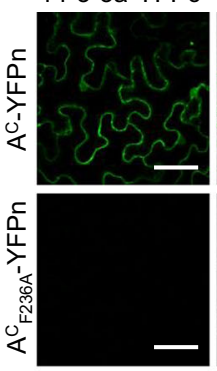

d

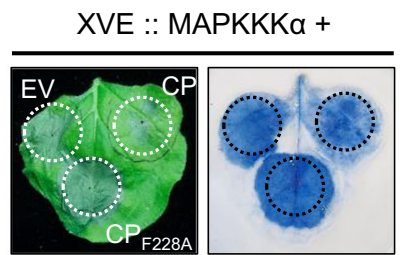

b

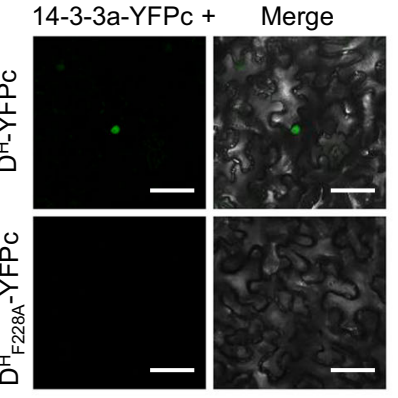

e

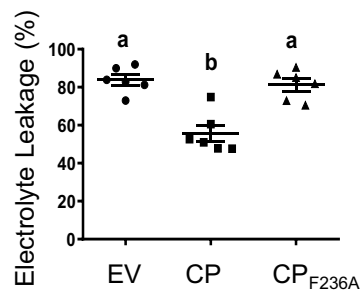

14-3-3a-YFPn + Merge

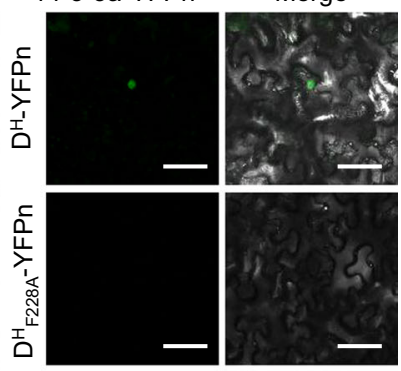

f

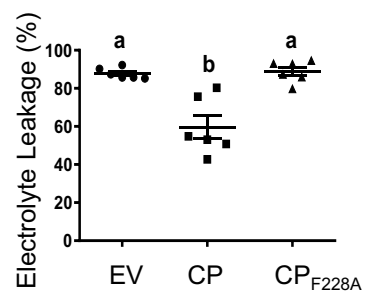

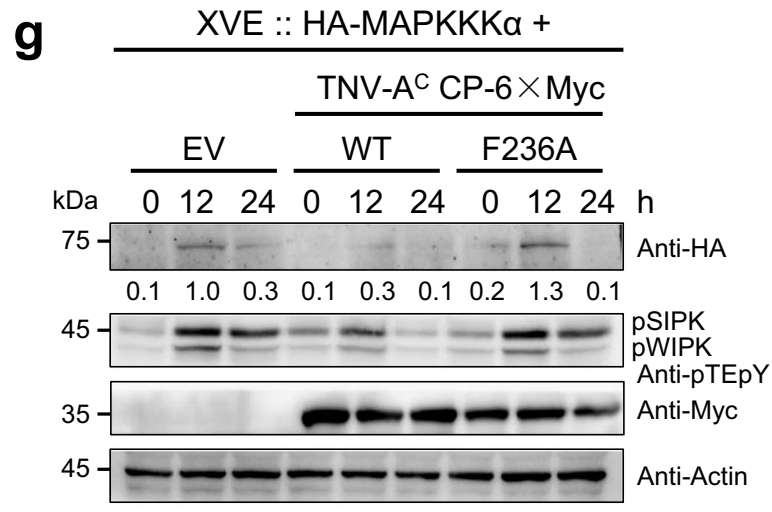

h

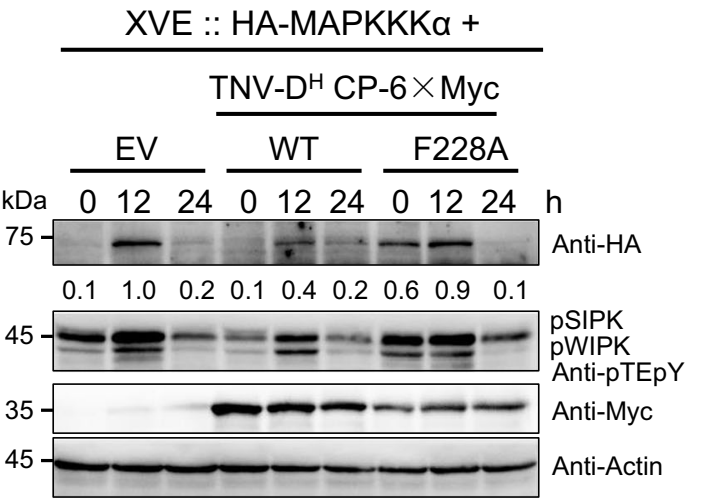

j

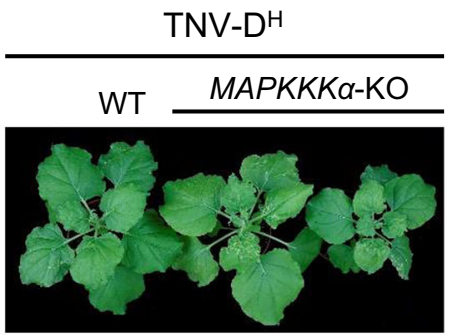

k
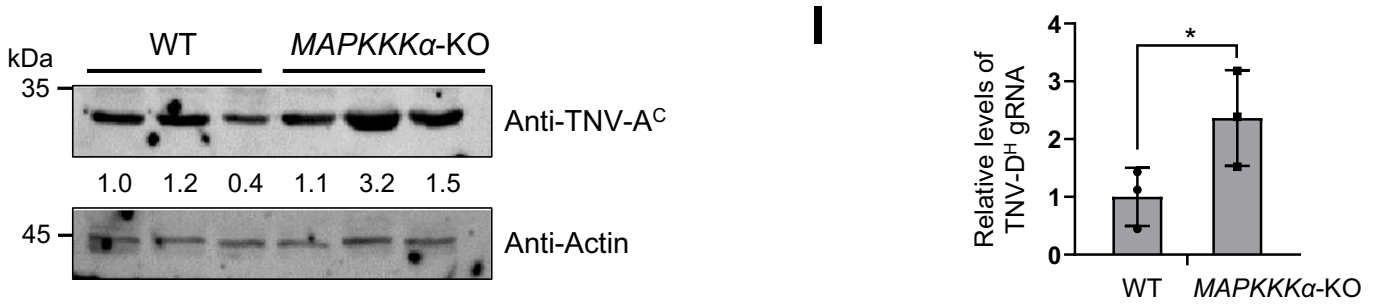

Previous studies indicated that bacterial pathogen effectors target 14-3-3 proteins. For example, the XopQ effector from Xanthomonas oryzae pv. oryzae interacts with several rice 14-3-3 proteins to regulate immunity ${ }^{73}$. The effectors XopQ, XopE1, XopE2, and XopO from Xanthomonas euvesicatoria interact with multiple tomato 14-3-3 proteins to suppress ETI ${ }^{74,75}$. The effector

XopN from Xanthomonas campestris pv. vesicatoria interacts with a tomato atypical receptor-like kinase 1 (TARK1) and TFT1 to suppress $\mathrm{PTI}^{76,77}$. Here, for the first time, we demonstrate that 14-3-3a is targeted by a viral CP effector. Based on our findings, we propose a model illustrating the MAPKKKamediated defense against viruses and how viral CP counteracts 
Fig. 9 Perturbation of Nb14-3-3a-MAPKKK $\alpha$ functional module by the CP is a common strategy employed by necroviruses. $\mathbf{a}$, $\mathbf{b}$ BiFC analysis of the interaction between $\mathrm{CP}$ of TNV-AC (a) or TNV-D $\mathrm{D}^{\mathrm{H}}(\mathbf{b})$ and 14-3-3a. The indicated combinations of different proteins were transiently co-expressed in $\mathrm{N}$. benthamiana leaves. Confocal analysis was performed at $3 \mathrm{dpi}$. The experiments were repeated three times and representative results are shown. Scale bars $=50 \mu \mathrm{m}$. c, d CP inhibits MAPKKK $\alpha$-induced cell death. Agrobacterium carrying wild-type TNV-AC (c) or TNV-DH (d) CP or their variants was coinfiltrated with Agrobacterium containing HA-MAPKKK $\alpha$ controlled by an estradiol-inducible system into different leaf regions. Empty vector (EV) served as the negative control. $\beta$-estradiol was applied $48 \mathrm{~h}$ after agroinfiltration. Leaves were stained by trypan blue and representative photographs were taken 3 days after estradiol treatment. e, $\mathbf{f}$ Quantification of cell death by measuring electrolyte leakage of leaf regions shown in (c) and (d). Error bars indicate \pm SD of the mean ( $n=6$ biologically independent plants). Different letters in the chart denote statistically significant differences among different groups according to the one-way ANOVA analysis with Tukey's multiple comparison test $(P<0.05) \cdot \mathbf{g}, \mathbf{h}$ CP affects MAPKKK $\alpha$ protein stability and MAPK activation in non-transgenic N. benthamiana. Agrobacterium carrying CP or CP ${ }_{Y 194 A}$ was co-infiltrated with Agrobacterium containing HA-MAPKKK $\alpha$ controlled by an estradiol-inducible system into the leaves. Empty vector (EV) served as the negative control. In all, $30 \mu \mathrm{M} \beta$-estradiol was infiltrated into the leaves $48 \mathrm{~h}$ after agroinfiltration. Samples were collected at $0,12,24 \mathrm{~h}$ after $\beta$-estradiol treatment and subjected to western blot with different antibodies indicated on the right. Actin served as the loading control. The experiments were repeated three times with similar results. $\mathbf{i}, \mathbf{j}$ Phenotype observation of TNV-AC (i) or TNV-D ${ }^{H}(\mathbf{j})$-infected MAPKKK $\alpha$-KO plants. N. benthamiana leaves were inoculated with $100 \mathrm{ng}$ TNV-AC virions. Representative photographs were taken at 9 dpi. $\mathbf{k}$ Western blot analysis of TNV-AC CP levels in the plants shown in panel $\mathbf{i}$ using an anti-TNV-AC antibody. Actin served as the loading control. The experiment was repeated three times with similar results. I RT-qPCR analysis of TNV-DH genomic RNA levels in the plants shown in panel $\mathbf{j}$. Values represent \pm SD of the mean $(n=6$ biologically independent plants). An asterisk indicates the significant difference based on one-sided Student's $t$ test $\left({ }^{\star} P=0.0357\right)$.

the MAPKKKa-mediated immunity (Fig. 8c). Upon perception of viral infection, MAPKKKa is activated by some unknown components and 14-3-3a binds to and enhances the stability of MAPKKKa, leading to the activation of MAPK signaling and concomitant induction of plant defense-related genes, which may contribute to immunity against virus infection. To counteract the MAPKKKa-mediated antiviral immunity, $\mathrm{CP}$ is translated from viral RNA (vRNA) and increased amount of $\mathrm{CP}$ accumulates during the viral infection, it interacts with 14-3-3a and disrupts the 14-3-3a-MAPKKKa module. The released MAPKKKa is degraded by the $26 \mathrm{~S}$ proteasome, leading to the impairment of MAPKKKa-mediated antiviral resistance (Fig. 8c). Our findings provide novel insights towards a better understanding of defense and counter-defense during plant-virus interplay. Our results also show that CPs of other necroviruses interfere with 14-3-3aMAPKKKa immune signaling module as a counter-defensive strategy to promote viral infection. Moreover, we also noted that $\mathrm{CPs}$ of numerous viruses in the family Tombusviridae contain the 14-3-3-binding-like motif ${ }^{78}$, implying a general mechanism employed by the viruses in the Tombusviridae to subvert plant immunity.

In summary, our findings described here deepen our understanding of the MAPKKKa-mediated defense against viruses and reveal a novel mechanism for the viral $\mathrm{CP}$ in counteracting MAPKKKa-mediated antiviral immunity.

\section{Methods \\ Plant materials and growth conditions. Nicotiana benthamiana plants were grown in a growth chamber at $23-24^{\circ} \mathrm{C}$ with a 15 -h-light/9-h-dark cycle.}

Generation of transgenic $\boldsymbol{N}$. benthamiana plants. $14-3-3 a-\mathrm{OE}$ and $14-3-3 a-\mathrm{KD}$ transgenic $N$. benthamiana plants were generated by Agrobacterium-mediated transformation with binary vectors 14-3-3a-3 $\times$ Flag and 14-3-3a-RNAi, respectively. MAPKKKa-KO transgenic $N$. benthamiana plants were generated by Agrobacterium-mediated transformation with binary vector BGK01-MAPKKKa. Single guide RNA targeting open reading frame of MAPKKKa was designed using CRISPR-P 2.0 design tool (http://crispr.hzau.edu.cn/CRISPR2/). Plasmids were transformed into A. tumefaciens strain EHA105. Leaf disc transformation was performed to generate the transgenic $N$. benthamiana plants ${ }^{79}$. Western blots with anti-14-3-3a antibodies were performed to screen the positive 14-3-3a-OE and 14$3-3 a-K D$ transgenic plants. To screen the positive $N b M A P K K K \alpha$ knockout plants, DNA fragment corresponding to the gRNA-targeted DNA sequence regions was amplified from genomic DNA of transgenic plants using corresponding primers listed in Supplementary Data 6, and DNA sequencing was carried out to examine the insertion or deletion at the target site.

Construction of plasmids. BBSV derivatives used in this study were generated from pCB301-BBSV ${ }^{80}$. The sequence of sfGFP11 and linker was amplified using synthetic oligos and introduced into N-terminal of CP in BBSV infectious clone using reverse PCR to generate BBSV-sfGFP ${ }_{11}$. Single amino acid mutation within the BBSV CP was constructed by using the QuickChange Site-Directed Mutagenesis Kit (Agilent Technologies, Santa Clara, CA, USA) according to the manufacturer's instructions.

For transient expression in plants, plasmid pMDC32-CP $\mathrm{P}_{\mathrm{Y} 194 \mathrm{~A}}$ and $\mathrm{pMDC} 32$ $\mathrm{CP}_{\mathrm{Y} 194 \mathrm{~F}}$ were constructed by amplifying the $\mathrm{CP}$ fragments from infectious clones of mutant BBSV containing Y194A or Y194F respectively and recombined into Kpn I and Spe I-digested pMDC32 plasmid ${ }^{81}$ using the Seamless Assembly Cloning Kit (Clone Smarter). Nb14-3-3a was amplified from the cDNA of N. benthamiana and cloned into pMD19-T vector (Takara). The obtained plasmid was used for sitedirected mutagenesis by using a QuickChange Site-Directed Mutagenesis Kit. The DNA fragment encoding wild-type or mutant Nb14-3-3a was amplified and cloned into pMDC32-3×Flag using the Seamless Assembly Cloning Kit (Clone Smarter) to generate $14-3-3 \mathrm{a}-3 \times$ Flag, $14-3-3 \mathrm{a}_{3 \mathrm{E}^{-}} 3 \times$ Flag, and 14-3-3a $\mathrm{QQR}-3 \times$ Flag respectively. The construction of the plasmid pMDC32-3×Flag was described previously ${ }^{82}$. For the construction of HA-MAPKKKa $\alpha_{K 236 \mathrm{M}}$, NbMAPKKKa was amplified from the cDNA of $N$. benthamiana and cloned into the pGD-3 $\times$ HA vector, an updated version of $\mathrm{pGD}$ vector ${ }^{83}$ that was engineered with an $\mathrm{N}$-terminal triple HA epitope. The resultant plasmid was used for site-directed mutagenesis using a QuickChange Site-Directed Mutagenesis Kit. To generate XVE::HA-MAPKKKa, MAPKKKa with a N-terminal triple HA epitope was amplified and recombined into pDONR207 vector (Invitrogen) by BP recombination followed by LR recombination into destination vector SPDK2130 under the estradiol-inducible system $^{84}$. The other plasmids including pMDC32-CP, CP-3×Flag, and GFP-3×Flag were described previously ${ }^{80}$.

For TRV-mediated gene silencing, the cDNA fragments corresponding to the putative $N b M E K 2, N b S I P K$ and $N b W I P K$ were amplified using CDNA of $N$. benthamiana and cloned into pYL156 ${ }^{85}$.

For BiFC assay, the 14-3-3a gene and its mutants (14-3-3 $\mathrm{a}_{3 \mathrm{E}}$ and $\left.14-3-3 \mathrm{a}_{\mathrm{QQR}}\right)$, $\mathrm{CP}$ wild-type gene and its mutants $\left(\mathrm{CP}_{1-187}, \mathrm{CP}_{46-232}, \mathrm{CP}_{\mathrm{Y} 194 \mathrm{~A}}\right.$ and $\left.\mathrm{CP}_{\mathrm{Y} 194 \mathrm{~F}}\right)$, and MAPKKK $\alpha_{\mathrm{K} 236 \mathrm{M}}$ were amplified respectively and cloned into binary vectors pSPYNE-35S or pSPYCE-35S 86 .

To generate 14-3-3a-RNAi and MAPKKKa-RNAi vector, 300 nucleotides from 14-3-3a cDNA and 1-322 nucleotides from MAPKKKa cDNA were amplified and recombined into pDONR207 vector (Invitrogen) by BP recombination respectively. The interference fragments were then introduced into the destination vector pHELLSGATE $8^{87}$ via LR reaction to generate RNAi expression vector.

For prokaryotic expression experiments, $\mathrm{Nb14-3-3a}$ gene was amplified and cloned into EcoR I-digested pGEX-KG plasmid to generate GST-14-3-3a. His-CP His- $\mathrm{CP}_{\mathrm{Y} 194 \mathrm{~A}}$, and His- $\mathrm{CP}_{\mathrm{Y} 194 \mathrm{~F}}$ were constructed by amplifying the $\mathrm{CP}$ fragments from the infectious clones of wild-type or mutant BBSV and ligated into pET30a $(+)$ at the BamHI and SalI restriction sites. The construction of GFP-His was described previously ${ }^{80}$.

For PVX infection assay, BBSV CP and $\mathrm{CP}_{\mathrm{Y} 194 \mathrm{~A}}$ were cloned into the pND108 vector $^{88}$ at the XhoI and ApaI sites to yield PVX-CP and PVX-CP ${ }_{\mathrm{Y} 194 \mathrm{~A}}$.

The primers used for constructing these plasmids are listed in Supplementary Data 6 and DNA sequencing was performed to confirm the correctness of all the plasmids.

Agroinfiltration and viral inoculation. All plasmids were transformed into Agrobacterium tumefaciens strains GV3101 or EHA105 by freeze-thaw transformation ${ }^{89}$. After being cultured in LB medium containing $25 \mu \mathrm{g} / \mathrm{mL}$ kanamycin and $100 \mu \mathrm{g} / \mathrm{mL}$ rifampicin at $28^{\circ} \mathrm{C}$ for $14-16 \mathrm{~h}$, Agrobacterium cells were harvested and resuspended in infiltration media $\left(10 \mathrm{mM} \mathrm{MgCl}_{2}, 150 \mu \mathrm{M}\right.$ 
acetosyringone, and $10 \mathrm{mM}$ MES ( $\mathrm{pH}$ 5.6)) for $2-4 \mathrm{~h}$ at room temperature followed by infiltration into four-week-old $N$. benthamiana leaves using needle-free syringes. For co-expression assays, Agrobacterium containing different constructs were mixed in a 1:1 or 1:1:1 ratio with a final $\mathrm{OD}_{600}=0.3$. For the XVE::HA-MAPKKKa (wild-type or K236M) expression, $30 \mu \mathrm{M} 17-\beta$-estradiol were infiltrated into the $N$. benthamiana leaves $48 \mathrm{~h}$ after agroinfiltration.

For viral infection analysis, $300 \mathrm{ng}$ of $\mathrm{BBSV}$ or TNV- $\mathrm{A}^{\mathrm{C}}$ virions mixed with FES inoculation buffer $(0.1 \mathrm{M}$ glycine, $0.06 \mathrm{M}$ dipotassium phosphate, $1 \%$ sodium pyrophosphate decahydrate, $1 \%$ bentonite, $1 \%$ celite, $\mathrm{pH} 8.5$ ) at a 1:1 ratio followed by mechanical inoculation onto $4-5$ leaf stage $N$. benthamiana plants. RNA transcripts of TNV-D ${ }^{\mathrm{H}}$ were inoculated as described previously ${ }^{82}$. The SmaI-linearized plasmid $\mathrm{A}_{172 S^{90}}(200 \mathrm{ng}$ ) were used as templates for in vitro transcription with T7 RNA polymerase (Promega). Freshly prepared in vitro transcripts were analyzed by $1 \%(\mathrm{wt} / \mathrm{vol})$ agarose gel electrophoresis to evaluate the quality of the RNA transcripts. The RNA transcripts were then mixed with an equal volume of FES inoculation buffer at a 1:1 ratio followed by mechanical inoculation onto 4-5 leaf stage $N$. benthamiana plants.

RNA-Seq analysis. The leaf samples from Mock- and BBSV-inoculated plants were collected at the indicated dpi. Three leaves from different plants were collected as one biological replicate, and three biological replicates were used for each group. Total RNAs were extracted using TRIzol reagent (Invitrogen). After quantification and qualification, total RNAs were pooled for cDNA library construction. cDNA library preparation and sequencing were carried out on an Illumina NovaSeq 6000 platform with 150-bp pair-end reads in Novogene (Beijing, China). Total reads were mapped to the Nicotiana benthamiana transcriptome (http://sefapps02.qut.edu.au/downloads/Nbv0.5.genome.fa.gz) using Hisat2 (v2.0.5), and the mapped reads of each sample were assembled by StringTie (v1.3.3b) in a reference-based approach. The expression level of each gene was calculated based on expected number of Fragments Per Kilobase of transcript sequence per Million's base pairs sequenced (FPKM). Differential expression analysis of two groups was performed using the DESeq2 R package (1.20.0). The resulting $P$ values were adjusted using Benjamini and Hochberg's approach for controlling the false discovery rate $(P$ adj). $P$ adj $<0.05$ and $\mid \log 2$ (foldchange) $\mid>1$ were set as the threshold for significantly differential expression.

Mass spectrometry analysis. Silver-stained protein band as indicated by the rectangle in Fig. $3 c$ was excised from SDS-PAGE gels, the gel band was destained with Sigma Proteosilver kit (PROTSIL1, Sigma), and then reduced with $10 \mathrm{mM}$ DTT, alkylated with $55 \mathrm{mM}$ iodoacetamide, and digested with trypsin ( $\mathrm{pH} 8.5)$ at $37^{\circ} \mathrm{C}$ for $12 \mathrm{~h}$. The digested peptides were separated by nanoscale C18 reversephase liquid chromatography (Waters), and then electro-sprayed into a Q-Exactive high-resolution mass spectrometer (Thermo Fisher Scientific) at the Mass Spectrometry Facility of China Agricultural University. Protein identification was performed by searching against the protein database of either the National Center for Biotechnology Information (NCBI) or the N. benthamiana sequence v1.0.1 proteome (ftp://ftp.solgenomics.net/genomes/Nicotiana_benthamiana) using Mascot Server (version 2.5.1, Matrix Science).

BiFC assay. Agrobacterium harboring various BiFC constructs were mixed with a final $\mathrm{OD}_{600}=0.3$ and co-infiltrated into 4 -week-old $N$. benthamiana leaves. At 3 dpi, the leaf samples were observed under a Zeiss LSM880 confocal microscope. YFP signals were excited at $514 \mathrm{~nm}$.

Co-immunoprecipitation (Co-IP). Co-IP was performed according to previously described methods with minor modifications ${ }^{91}$. $N$. benthamiana leaves were coinfiltrated with the mixture of Agrobacterium containing various constructs. At 3 dpi, leaves were harvested and ground in liquid nitrogen followed by mixing with two volumes of freshly prepared protein extraction buffer $[50 \mathrm{mM}$ Tris- $\mathrm{HCl}(\mathrm{pH}$ 7.5), $150 \mathrm{mM} \mathrm{NaCl}, 1 \mathrm{mM}$ EDTA, $10 \%$ (v/v) glycerol, $2 \%(\mathrm{w} / \mathrm{v})$ poly-

vinylpyrrolidone, $10 \mathrm{mM}$ dithiothreitol (DTT), $1 \times$ protease inhibitor cocktail, and $0.5 \%(\mathrm{v} / \mathrm{v})$ Triton X-100]. After incubation on ice for $40 \mathrm{~min}$, the crude extract was centrifugated at $17,000 \times g$ for $30 \mathrm{~min}$ and the supernatant was incubated with antiFlag M2 Affinity Gel (Sigma-Aldrich) at $4{ }^{\circ} \mathrm{C}$ for $4 \mathrm{~h}$. The beads were washed three times with IP buffer [50 mM Tris-HCl (pH 7.5), $150 \mathrm{mM} \mathrm{NaCl}, 1 \mathrm{mM}$ EDTA, 10\% $(\mathrm{v} / \mathrm{v})$ glycerol, and $0.1 \%(\mathrm{v} / \mathrm{v})$ Triton X-100] and then analyzed by western blot with anti-Flag (1:5000, Sigma, Cat. No. F1804) and anti-CP (1:2000, produced by Beijing Protein Innovation Co., Ltd) antibodies.

Expression and purification of recombinant proteins. Protein purification was performed as described previously ${ }^{82}$. Expression constructs were transformed into E. coli strains BL21 or Rosetta. Cultures were grown at $37^{\circ} \mathrm{C}$ until $\mathrm{OD}_{600}=0.8$, and protein expression was induced by $0.2 \mathrm{mM}$ isopropyl- $\beta$-D-thiogalactopyranoside (IPTG) at $18^{\circ} \mathrm{C}$ overnight. Cells were then collected and subjected to protein purification using Glutathione Sepharose ${ }^{\mathrm{TM}} 4$ Fast Flow (GE Healthcare) or NiNTA agarose (QIAGEN) according to the manufacturer's instructions.
GST pull-down assay. GST pull-down assay was conducted as described previously with minor modifications ${ }^{80}$. About $20 \mu \mathrm{g}$ of purified GST-14-3-3a or GST proteins were incubated with $15 \mu \mathrm{L}$ Glutathione Sepharose ${ }^{\mathrm{TM}} 4$ Fast Flow (GE Healthcare) in $1 \mathrm{~mL}$ binding buffer $(50 \mathrm{mM}$ Tris- $\mathrm{HCl}(\mathrm{pH} 7.5), 250 \mathrm{mM} \mathrm{NaCl}$, $5 \mathrm{mM}$ DTT, $0.2 \%(\mathrm{v} / \mathrm{v})$ glycerol, and $0.6 \%(\mathrm{v} / \mathrm{v})$ Triton X-100) for $1.5 \mathrm{~h}$ at room temperature. The supernatant was removed after centrifugation, and $10 \mu \mathrm{g}$ of Histagged proteins in $1 \mathrm{~mL}$ of binding buffer were incubated with the GST beads at room temperature for $2 \mathrm{~h}$. The GST beads were washed six times with washing buffer (50 mM Tris- $\mathrm{HCl}(\mathrm{pH} 7.5), 500 \mathrm{mM} \mathrm{NaCl}, 0.2 \%$ (v/v) glycerol, and $0.6 \%(\mathrm{v} /$ v) Triton $\mathrm{X}-100)$ and detected by western blot with anti-His (1:5000, EASYBIO, Cat. No. BE7001) and anti-GST antibodies (1:5000, Genscript, Cat. No. A00866).

Trypan blue staining. Trypan blue staining was performed as previously described with minor modifications ${ }^{92}$. The infiltrated leaves were pretreated with ethanol for $3 \mathrm{~min}$, and then combined with trypan blue staining solution prepared in $40 \mathrm{~mL}$ of ethanol, $10 \mathrm{~mL}$ of lactic acid, $10 \mathrm{~mL}$ of water phenol, $10 \mathrm{~mL}$ of glycerol, and $10 \mathrm{~mL}$ of sterile water with $15 \mathrm{mg}$ of Trypan blue. The samples were placed in boiling water for $10 \mathrm{~min}$ and incubated at room temperature for $8 \mathrm{~h}$. The samples were destained using chloral hydrate $(2.5 \mathrm{~g} / \mathrm{mL}$ sterile water) followed by photography.

Electrolyte-leakage assay. The electrolyte-leakage assay was performed as described previously with minor modifications ${ }^{93}$. Two leaf discs $(9 \mathrm{~mm}$ in diameter) were collected from infiltrated areas of six to eight plants and floated in 15$\mathrm{mL}$ tubes containing $10 \mathrm{~mL}$ of MilliQ-water for $1 \mathrm{~h}$ at $25^{\circ} \mathrm{C}$ with shaking at $165 \mathrm{rpm}$. Conductivity was measured using a DDS-12DW conductivity meter (BANTE) to obtain S1 value. The samples were placed in boiling water for $45 \mathrm{~min}$, followed by shaking at $25^{\circ} \mathrm{C}$ for $1 \mathrm{~h}$, and measured to obtain the $\mathrm{S} 2$ value. The ratio of S1 to S2 was calculated as electrolyte leakage.

RNA extraction and reverse transcription-quantitative real-time PCR (RTqPCR). Total RNA was extracted using the TRIzol Reagent (Invitrogen) according to the manufacturer's instructions. RT-qPCR was performed as previously reported ${ }^{94}$. Briefly, $3 \mu \mathrm{g}$ of total RNA was treated with DNase I (Takara), and cDNA was reversely transcribed with M-MLV reverse transcriptase (Promega). qPCR analysis was performed with CFX Manger (Bio-Rad) using $2 \times$ SsoFast EvaGreen Supermix (Bio-Rad). Elongation factor $1 \alpha(E F-1 \alpha)$ gene served as the internal control. All primer pairs used for RT-qPCR analyses are listed in Supplementary Data 6.

MAPK activation assay. MAPK activation assay was performed as previously described with minor modifications ${ }^{95}$. After agroinfiltration and induction of MAPKKKa expression as described above, total protein was extracted in protein extraction buffer [50 mM Tris- $\mathrm{HCl}(\mathrm{pH} 7.5), 150 \mathrm{mM}$ of NaCl, $0.5 \%$ Triton X-100, $1 \%(\mathrm{v} / \mathrm{v})$ protease inhibitor cocktail (Roche), $1 \mathrm{mM}$ of $\mathrm{Na}_{3} \mathrm{VO}_{4}, 1 \mathrm{mM}$ of $\mathrm{NaF}$, and $20 \mathrm{mM}$ of $\beta$-glycerophosphate), and detected by western blot with anti-Phosphop44/42 MAPK antibody (pTEpY) (1:2000, Cell Signaling Technology, Cat. No. 4370).

Competitive Co-IP assay. The leaves infiltrated with 14-3-3a-3×Flag and HAMAPKKKa ${ }_{K 236 \mathrm{M}}$ were harvested at $3 \mathrm{dpi}$. Total protein was extracted in extraction buffer (50 mM Tris- $\mathrm{HCl}$ (pH 7.5), $150 \mathrm{mM} \mathrm{NaCl}, 1 \mathrm{mM}$ EDTA, 10\% (v/v) glycerol, $2 \%(\mathrm{w} / \mathrm{v})$ polyvinylpyrrolidone, $10 \mathrm{mM}$ dithiothreitol (DTT), $1 \times$ protease inhibitor cocktail, and $0.5 \%(\mathrm{v} / \mathrm{v})$ Triton X-100) on ice for $30 \mathrm{~min}$, followed by centrifugation at $17,000 \times \mathrm{g}$ for $30 \mathrm{~min}$. Then increasing amounts of purified His-CP $(20 \mu \mathrm{g}, 40 \mu \mathrm{g})$ or His- $\mathrm{CP}_{\mathrm{Y} 194 \mathrm{~A}}(40 \mu \mathrm{g})$ were added to the supernatant and incubated with anti-Flag M2 Affinity Gel (Sigma-Aldrich). The precipitates were washed three times with IP buffer at $4^{\circ} \mathrm{C}$ and analyzed by western blot with anti-Flag (1:5000, Sigma, Cat. No. F1804), anti-CP (1:2000, produced by Beijing Protein Innovation Co., Ltd) and anti-HA antibodies (1:5000, EASYBIO, Cat. No. BE7001).

Competitive pull-down assay. A competitive pull-down assay was conducted as previously described with minor modifications ${ }^{96}$. MAPKKKa $\alpha_{K 236 \mathrm{M}^{-}}$GFP extracts were immunoprecipitated by $20 \mu \mathrm{L}$ GFP-Trap beads (ChromoTek, German) as described in the Co-IP part. $100 \mu \mathrm{g}$ E. coli-expressed His-14-3-3a was added in $1 \mathrm{~mL}$ binding buffer [50 mM Tris- $\mathrm{HCl}$ (pH 7.5), $250 \mathrm{mM} \mathrm{NaCl}, 5 \mathrm{mM}$ DTT, $1 \mathrm{mM}$ PMSF, and $1 \times$ protease inhibitor cocktail] and incubated at $4{ }^{\circ} \mathrm{C}$ for $2 \mathrm{~h}$. After two washes with washing buffer ( $50 \mathrm{mM}$ Tris- $\mathrm{HCl}$ ( $\mathrm{pH} 7.5), 250 \mathrm{mM} \mathrm{NaCl}, 5 \mathrm{mM}$ DTT, $1 \mathrm{mM}$ PMSF, $1 \times$ protease inhibitor cocktail and $0.2 \%(\mathrm{v} / \mathrm{v})$ Triton X-100), $80 \mu \mathrm{g}$, $40 \mu \mathrm{g}, 20 \mu \mathrm{g}$ His-CP or $80 \mu \mathrm{g}, 40 \mu \mathrm{g}$ His- $\mathrm{CP}_{\mathrm{Y} 194 \mathrm{~A}}$ was added to the $1 \mathrm{~mL}$ corresponding samples and incubated at $4{ }^{\circ} \mathrm{C}$ for additional $1 \mathrm{~h}$. After three washes with washing buffer, samples were analyzed by western blot with anti-GFP (1:5000, MBL, Cat. No. 598), anti-CP (1:2000, produced by Beijing Protein Innovation Co., Ltd) and anti-14-3-3a antibodies (1:1000, produced by Beijing Protein Innovation Co., Ltd). 
Reporting summary. Further information on research design is available in the Nature Research Reporting Summary linked to this article.

\section{Data availability}

Data supporting the findings of this work are available within the paper and its Supplementary Information files, or from the corresponding author upon request. The raw RNA-seq data are available in the NCBI database under accession code PRJNA767174. Source data are provided with this paper.

Received: 2 March 2021; Accepted: 17 January 2022; Published online: 07 February 2022

\section{References}

1. Jones, J. D. \& Dangl, J. L. The plant immune system. Nature 444, 323-329 (2006).

2. Wang, W., Feng, B., Zhou, J. M. \& Tang, D. Plant immune signaling: advancing on two frontiers. J. Integr. Plant Biol. 62, 2-24 (2020).

3. Peng, Y., van Wersch, R. \& Zhang, Y. Convergent and divergent signaling in PAMP-triggered immunity and effector-triggered immunity. Mol. PlantMicrobe Interact. 31, 403-409 (2018)

4. Coll, N. S., Epple, P. \& Dangl, J. L. Programmed cell death in the plant immune system. Cell Death Differ. 18, 1247-1256 (2011).

5. Moon, J. Y. \& Park, J. M. Cross-talk in viral defense signaling in plants. Front. Microbiol. 7, 2068 (2016).

6. Calil, I. P. \& Fontes, E. P. B. Plant immunity against viruses: antiviral immune receptors in focus. Ann. Bot. 119, 711-723 (2017).

7. Meier, N., Hatch, C., Nagalakshmi, U. \& Dinesh-Kumar, S. P. Perspectives on intracellular perception of plant viruses. Mol. Plant Pathol. 20, 1185-1190 (2019).

8. Yang, H. et al. BAK1 and BKK1 in Arabidopsis thaliana confer reduced susceptibility to Turnip crinkle virus. Eur. J. Plant Pathol. 127, 149-156 (2010).

9. Korner, C. J. et al. The immunity regulator BAK1 contributes to resistance against diverse RNA viruses. Mol. Plant-Microbe Interact. 26, 1271-1280 (2013).

10. Nicaise, V. \& Candresse, T. Plum pox virus capsid protein suppresses plant pathogen-associated molecular pattern (PAMP)-triggered immunity. Mol. Plant Pathol. 18, 878-886 (2017).

11. Liu, J. Z. et al. Soybean homologs of MPK4 negatively regulate defense responses and positively regulate growth and development. Plant Physiol. 157, 1363-1378 (2011).

12. Carvalho, C. M. et al. Regulated nuclear trafficking of rpL10A mediated by NIK1 represents a defense strategy of plant cells against virus. PLoS Pathog. 4 , e1000247 (2008).

13. Zorzatto, C. et al. NIK1-mediated translation suppression functions as a plant antiviral immunity mechanism. Nature 520, 679-682 (2015).

14. Kong, J. et al. The Cucumber mosaic virus movement protein suppresses PAMP-triggered immune responses in Arabidopsis and tobacco. Biochem. Biophys. Res. Commun. 498, 395-401 (2018).

15. Zvereva, A. S. et al. Viral protein suppresses oxidative burst and salicylic aciddependent autophagy and facilitates bacterial growth on virus-infected plants. N. Phytol. 211, 1020-1034 (2016).

16. Tsuda, K. \& Katagiri, F. Comparing signaling mechanisms engaged in patterntriggered and effector-triggered immunity. Curr. Opin. Plant Biol. 13, 459-465 (2010).

17. Yuan, M., Ngou, B. P. M., Ding, P. \& Xin, X. F. PTI-ETI crosstalk: an integrative view of plant immunity. Curr. Opin. Plant Biol. 62, 102030 (2021).

18. Pitzschke, A., Schikora, A. \& Hirt, H. MAPK cascade signalling networks in plant defence. Curr. Opin. Plant Biol. 12, 421-426 (2009).

19. Lu, Y. \& Tsuda, K. Intimate association of PRR- and NLR-mediated signaling in plant immunity. Mol. Plant-Microbe Interact. 34, 3-14 (2021)

20. Thulasi Devendrakumar, K., Li, X. \& Zhang, Y. MAP kinase signalling: interplays between plant PAMP- and effector-triggered immunity. Cell. Mol. Life Sci. 75, 2981-2989 (2018).

21. Bi, G. et al. Receptor-like cytoplasmic kinases directly link diverse pattern recognition receptors to the activation of mitogen-activated protein kinase cascades in Arabidopsis. Plant Cell 30, 1543-1561 (2018)

22. Zipfel, C. et al. Perception of the bacterial PAMP EF-Tu by the receptor EFR restricts Agrobacterium-mediated transformation. Cell 125, 749-760 (2006).

23. Sun, T. et al. Antagonistic interactions between two MAP kinase cascades in plant development and immune signaling. EMBO Rep. 19, e45324 (2018).

24. Gao, M. et al. MEKK1, MKK1/MKK2 and MPK4 function together in a mitogen-activated protein kinase cascade to regulate innate immunity in plants. Cell Res. 18, 1190-1198 (2008).
25. Suarez-Rodriguez, M. C. et al. MEKK1 is required for flg22-induced MPK4 activation in Arabidopsis plants. Plant Physiol. 143, 661-669 (2007)

26. Tsuda, K. et al. Dual regulation of gene expression mediated by extended MAPK activation and salicylic acid contributes to robust innate immunity in Arabidopsis thaliana. PLoS Genet. 9, e1004015 (2013).

27. Zhang, S. \& Klessig, D. F. The tobacco wounding-activated mitogen-activated protein kinase is encoded by SIPK. Proc. Natl Acad. Sci. USA 95, 7225-7230 (1998).

28. Zhang, S. \& Klessig, D. F. Resistance gene N-mediated de novo synthesis and activation of a tobacco mitogen-activated protein kinase by Tobacco mosaic virus infection. Proc. Natl Acad. Sci. USA 95, 7433-7438 (1998).

29. Zhang, S., Liu, Y. \& Klessig, D. F. Multiple levels of tobacco WIPK activation during the induction of cell death by fungal elicitins. Plant J. 23, 339-347 (2000).

30. Yang, K. Y., Liu, Y. \& Zhang, S. Activation of a mitogen-activated protein kinase pathway is involved in disease resistance in tobacco. Proc. Natl Acad. Sci. USA 98, 741-746 (2001).

31. Ekengren, S. K., Liu, Y., Schiff, M., Dinesh-Kumar, S. P. \& Martin, G. B. Two MAPK cascades, NPR1, and TGA transcription factors play a role in Ptomediated disease resistance in tomato. Plant J. 36, 905-917 (2003).

32. del Pozo, O., Pedley, K. F. \& Martin, G. B. MAPKKKa is a positive regulator of cell death associated with both plant immunity and disease. EMBO J. 23, 3072-3082 (2004)

33. Eschen-Lippold, L. et al. Bacterial AvrRpt2-like cysteine proteases block activation of the arabidopsis mitogen-activated protein kinases, MPK4 and MPK11. Plant Physiol. 171, 2223-2238 (2016).

34. Zhang, J. et al. A Pseudomonas syringae effector inactivates MAPKs to suppress PAMP-induced immunity in plants. Cell Host Microbe 1, 175-185 (2007).

35. Wang, Y. et al. A Pseudomonas syringae ADP-ribosyltransferase inhibits Arabidopsis mitogen-activated protein kinase kinases. Plant Cell 22, 2033-2044 (2010)

36. $\mathrm{Hu}, \mathrm{T}$. et al. $\beta \mathrm{Cl}$ protein encoded in geminivirus satellite concertedly targets MKK2 and MPK4 to counter host defense. PLoS Pathog. 15, e1007728 (2019).

37. Park, E., Lee, H. Y., Woo, J., Choi, D. \& Dinesh-Kumar, S. P. Spatiotemporal monitoring of Pseudomonas syringae effectors via type III secretion using split fluorescent protein fragments. Plant Cell 29, 1571-1584 (2017).

38. Wesley, S. V. et al. Construct design for efficient, effective and highthroughput gene silencing in plants. Plant J. 27, 581-590 (2001)

39. Lorenzo, O., Piqueras, R., Sanchez-Serrano, J. J. \& Solano, R. Ethylene response factor 1 integrates signals from ethylene and jasmonate pathways in plant defense. Plant Cell 15, 165-178 (2003)

40. Mei, Y., Ma, Z., Wang, Y. \& Zhou, X. Geminivirus C4 antagonizes the HIR1mediated hypersensitive response by inhibiting the HIR1 self-interaction and promoting degradation of the protein. N. Phytol. 225, 1311-1326 (2020)

41. Bigeard, J., Colcombet, J. \& Hirt, H. Signaling mechanisms in patterntriggered immunity (PTI). Mol. Plant 8, 521-539 (2015)

42. Lozano-Duran, R. \& Robatzek, S. 14-3-3 proteins in plant-pathogen interactions. Mol. Plant-Microbe Interact. 28, 511-518 (2015).

43. Chahdi, A. \& Sorokin, A. Protein kinase A-dependent phosphorylation modulates $\beta_{1}$ Pix guanine nucleotide exchange factor activity through 14-3-3 $\beta$ binding. Mol. Cell. Biol. 28, 1679-1687 (2008).

44. Sluchanko, N. N., Sudnitsyna, M. V., Seit-Nebi, A. S., Antson, A. A. \& Gusev, N. B. Properties of the monomeric form of human $14-3-3 \zeta$ protein and its interaction with tau and HspB6. Biochemistry 50, 9797-9808 (2011).

45. Zhang, Y. et al. Nuclear localization of Beet black scorch virus capsid protein and its interaction with importina. Virus Res. 155, 307-315 (2011).

46. Zhang, X. et al. N-terminal basic amino acid residues of Beet black scorch virus capsid protein play a critical role in virion assembly and systemic movement. Virol. J. 10, 200 (2013).

47. King, A. M. Q., Adams, M. J., Carstens, E. B. \& Lefkowitz, E. J. Virus taxonomy: Ninth Report of the International Committee on Taxonomy of Viruses (Elsevier, 2011)

48. Yaffe, M. B. et al. The structural basis for 14-3-3:phosphopeptide binding specificity. Cell 91, 961-971 (1997).

49. Komatsu, K. et al. Viral-induced systemic necrosis in plants involves both programmed cell death and the inhibition of viral multiplication, which are regulated by independent pathways. Mol. Plant-Microbe Interact. 23, 283-293 (2010).

50. DuShane, J. K. \& Maginnis, M. S. Human DNA virus exploitation of the MAPK-ERK cascade. Int. J. Mol. Sci. 20, 3427 (2019).

51. Pleschka, S. RNA viruses and the mitogenic Raf/MEK/ERK signal transduction cascade. Biol. Chem. 389, 1273-1282 (2008).

52. Panteva, M., Korkaya, H. \& Jameel, S. Hepatitis viruses and the MAPK pathway: is this a survival strategy? Virus Res. 92, 131-140 (2003).

53. Bonjardim, C. A. Viral exploitation of the MEK/ERK pathway-a tale of vaccinia virus and other viruses. Virology 507, 267-275 (2017). 
54. Fischer, U. \& Droge-Laser, W. Overexpression of NtERF5, a new member of the tobacco ethylene response transcription factor family enhances resistance to Tobacco mosaic virus. Mol. Plant-Microbe Interact. 17, 1162-1171 (2004).

55. Zhang, K. et al. Selection of reference genes for gene expression studies in virus-infected monocots using quantitative real-time PCR. J. Biotechnol. 168 , 7-14 (2013).

56. Meng, X. et al. Phosphorylation of an ERF transcription factor by Arabidopsis MPK3/MPK6 regulates plant defense gene induction and fungal resistance. Plant Cell 25, 1126-1142 (2013).

57. Li, N., Han, X., Feng, D., Yuan, D. \& Huang, L. J. Signaling crosstalk between salicylic acid and ethylene/jasmonate in plant defense: do we understand what they are whispering? Int. J. Mol. Sci. 20, 671 (2019).

58. $\mathrm{Li}, \mathrm{S}$. et al. The hypersensitive induced reaction 3 (HIR3) gene contributes to plant basal resistance via an EDS1 and salicylic acid-dependent pathway. Plant J. 98, 783-797 (2019).

59. Niehl, A., Wyrsch, I., Boller, T. \& Heinlein, M. Double-stranded RNAs induce a pattern-triggered immune signaling pathway in plants. N. Phytol. 211, 1008-1019 (2016).

60. Aitken, A. 14-3-3 proteins: a historic overview. Semin. Cancer Biol. 16, 162-172 (2006).

61. Ferl, R. J., Manak, M. S. \& Reyes, M. F. The 14-3-3s. Genome Biol. 3 3010.3011-3010.3017 (2002).

62. Bridges, D. \& Moorhead, G. B. 14-3-3 proteins: a number of functions for a numbered protein. Sci. STKE 2005, re10 (2005).

63. Fu, H., Subramanian, R. R. \& Masters, S. C. 14-3-3 proteins: structure, function, and regulation. Annu. Rev. Pharmacol. Toxicol. 40, 617-647 (2000).

64. Denison, F. C., Paul, A. L., Zupanska, A. K. \& Ferl, R. J. 14-3-3 proteins in plant physiology. Semin. Cell Dev. Biol. 22, 720-727 (2011).

65. Oh, C. S. Characteristics of 14-3-3 proteins and their role in plant immunity. Plant Pathol. J. 26, 1-7 (2010).

66. Elmayan, T. et al. Regulation of reactive oxygen species production by a 14-33 protein in elicited tobacco cells. Plant Cell Environ. 30, 722-732 (2007)

67. Jahn, $\mathrm{T}$. et al. The 14-3-3 protein interacts directly with the C-terminal region of the plant plasma membrane H(+)-ATPase. Plant Cell 9, 1805-1814 (1997).

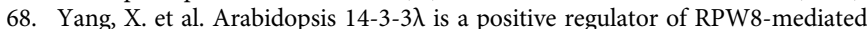
disease resistance. Plant J. 60, 539-550 (2009).

69. Oh, C. S., Pedley, K. F. \& Martin, G. B. Tomato 14-3-3 protein 7 positively regulates immunity-associated programmed cell death by enhancing protein abundance and signaling ability of MAPKKKa. Plant Cell 22, 260-272 (2010).

70. Jaumot, M. \& Hancock, J. F. Protein phosphatases 1 and 2A promote Raf-1 activation by regulating 14-3-3 interactions. Oncogene 20, 3949-3958 (2001).

71. Fritz, A. et al. Phosphorylation of serine 526 is required for MEKK3 activity, and association with 14-3-3 blocks dephosphorylation. J. Biol. Chem. 281, 6236-6245 (2006).

72. Lalle, M. et al. ZmMPK6, a novel maize MAP kinase that interacts with 14-3-3 proteins. Plant Mol. Biol. 59, 713-722 (2005)

73. Deb, S., Gupta, M. K., Patel, H. K. \& Sonti, R. V. Xanthomonas oryzae pv. oryzae XopQ protein suppresses rice immune responses through interaction with two 14-3-3 proteins but its phospho-null mutant induces rice immune responses and interacts with another 14-3-3 protein. Mol. Plant Pathol. 20, 976-989 (2019).

74. Teper, D. et al. Xanthomonas euvesicatoria type III effector XopQ interacts with tomato and pepper 14-3-3 isoforms to suppress effector-triggered immunity. Plant J. 77, 297-309 (2014).

75. Dubrow, Z. et al. Tomato 14-3-3 proteins are required for $X v 3$ disease resistance and interact with a subset of Xanthomonas euvesicatoria effectors. Mol. Plant-Microbe Interact. 31, 1301-1311 (2018).

76. Kim, J. G. et al. Xanthomonas T3S effector XopN suppresses PAMP-triggered immunity and interacts with a tomato atypical receptor-like kinase and TFT1. Plant Cell 21, 1305-1323 (2009).

77. Taylor, K. W. et al. Tomato TFT1 is required for PAMP-triggered immunity and mutations that prevent T3S effector XopN from binding to TFT1 attenuate Xanthomonas virulence. PLoS Pathog. 8, e1002768 (2012)

78. Navarro, J. A., Saiz-Bonilla, M., Sanchez-Navarro, J. A. \& Pallas, V. The mitochondrial and chloroplast dual targeting of a multifunctional plant viral protein modulates chloroplast-to-nucleus communication, RNA silencing suppressor activity, encapsidation, pathogenesis and tissue tropism. Plant $J$. 108, 197-218 (2021)

79. Horsch, R. B. et al. Leaf disc transformation. In Plant Molecular Biology Manua. (eds Gelvin, S. B., Schilperoort, R. A. \& Verma, D. P. S.), pp. 63-71 (Springer, 1989).

80. Wang, X. et al. Hsc70-2 is required for Beet black scorch virus infection through interaction with replication and capsid proteins. Sci. Rep. 8, 4526 (2018).

81. Curtis, M. D. \& Grossniklaus, U. A gateway cloning vector set for highthroughput functional analysis of genes in planta. Plant Physiol. 133, 462-469 (2003).
82. Gao, Z. et al. Tobacco necrosis virus- $\mathrm{A}^{\mathrm{C}}$ single coat protein amino acid substitutions determine host-specific systemic infections of Nicotiana benthamiana and soybean. Mol. Plant-Microbe Interact. 34, 49-61 (2021).

83. Goodin, M. M., Dietzgen, R. G., Schichnes, D., Ruzin, S. \& Jackson, A. O. pGD vectors: versatile tools for the expression of green and red fluorescent protein fusions in agroinfiltrated plant leaves. Plant J. 31, 375-383 (2002).

84. Zhang, Y. et al. TurboID-based proximity labeling reveals that UBR7 is a regulator of N NLR immune receptor-mediated immunity. Nat. Commun. 10, 3252 (2019)

85. Liu, Y., Schiff, M. \& Dinesh-Kumar, S. P. Virus-induced gene silencing in tomato. Plant J. 31, 777-786 (2002).

86. Walter, M. et al. Visualization of protein interactions in living plant cells using bimolecular fluorescence complementation. Plant J. 40, 428-438 (2004).

87. Helliwell, C. \& Waterhouse, P. Constructs and methods for high-throughput gene silencing in plants. Methods 30, 289-295 (2003).

88. Zhang, L. et al. Two virus-encoded RNA silencing suppressors, P14 of Beet necrotic yellow vein virus and S6 of Rice black streak dwarf virus. Sci. Bull. 50, 305-310 (2005).

89. Chen, H., Nelson, R. S. \& Sherwood, J. L. Enhanced recovery of transformants of Agrobacterium tumefaciens after freeze-thaw transformation and drug selection. Biotechniques 16, 664-668 (1994).

90. Molnar, A., Havelda, Z., Dalmay, T., Szutorisz, H. \& Burgyan, J. Complete nucleotide sequence of Tobacco necrosis virus strain DH and genes required for RNA replication and virus movement. J. Gen. Virol. 78, 1235-1239 (1997).

91. Yang, M. et al. Barley stripe mosaic virus $\gamma \mathrm{b}$ protein subverts autophagy to promote viral infection by disrupting the ATG7-ATG8 interaction. Plant Cell 30, 1582-1595 (2018).

92. Zhang, X. et al. Barley stripe mosaic virus infection requires PKA-mediated phosphorylation of $\gamma \mathrm{b}$ for suppression of both RNA silencing and the host cell death response. N. Phytol. 218, 1570-1585 (2018).

93. Liu, Z. et al. Plasma membrane CRPK1-mediated phosphorylation of 14-3-3 proteins induces their nuclear import to fine-tune CBF signaling during cold response. Mol. Cell 66, 117-128 (2017).

94. Liu, D. et al. Validation of reference genes for gene expression studies in virusinfected Nicotiana benthamiana using quantitative real-time PCR. PLOS ONE 7, e46451 (2012).

95. King, S. R. et al. Phytophthora infestans RXLR effector PexRD2 interacts with host MAPKKKe to suppress plant immune signaling. Plant Cell 26, 1345-1359 (2014).

96. Jia, $\mathrm{Q}$. et al. CLCuMuB $\beta \mathrm{C} 1$ subverts ubiquitination by interacting with NbSKP1s to enhance Geminivirus infection in Nicotiana benthamiana. PLoS Pathog. 12, e1005668 (2016).

\section{Acknowledgements}

We thank Drs. Jialin Yu, Xian-Bing Wang, Chenggui Han, and Ying Wang at China Agricultural University and Dr. Juan Xu at Zhejiang University for valuable suggestions We would like to thank Dr. Zhen Li (Mass Spectrometry Facility, CAU) for technical assistance with LC-MS/MS. This work was supported by the National Natural Science Foundation of China (32122070 and 31872637), the Chinese Universities Scientific Fund (2021TC112) and Beijing Outstanding University Discipline Program.

\section{Author contributions}

Y.Z. and Z.G. conceived the study and designed the experiments. Z.G. performed the experiments with the help of D.Z., X.W., X.Z., Z.W., and Q.Z. All authors discussed the data. D.L. provided suggestions for this work. Z.G., Y.Z., and S.P.D.-K. wrote and revised the manuscript.

\section{Competing interests}

The authors declare no competing interests.

\section{Additional information}

Supplementary information The online version contains supplementary material available at https://doi.org/10.1038/s41467-022-28395-5.

Correspondence and requests for materials should be addressed to Yongliang Zhang.

Peer review information Nature Communications thanks Steven A. Whitham and the other, anonymous, reviewer(s) for their contribution to the peer review of this work.

Reprints and permission information is available at http://www.nature.com/reprints

Publisher's note Springer Nature remains neutral with regard to jurisdictional claims in published maps and institutional affiliations. 
(c) (i) Open Access This article is licensed under a Creative Commons Attribution 4.0 International License, which permits use, sharing, adaptation, distribution and reproduction in any medium or format, as long as you give appropriate credit to the original author(s) and the source, provide a link to the Creative Commons license, and indicate if changes were made. The images or other third party material in this article are included in the article's Creative Commons license, unless indicated otherwise in a credit line to the material. If material is not included in the article's Creative Commons license and your intended use is not permitted by statutory regulation or exceeds the permitted use, you will need to obtain permission directly from the copyright holder. To view a copy of this license, visit http://creativecommons.org/ licenses/by/4.0/.

(C) The Author(s) 2022 